\title{
Vibrational Spectra of the Azabenzenes Revisited: Anharmonic Force Fields
}

\author{
A. Daniel Boese and Jan M. L. Martin \\ Department of Organic Chemistry, Weizmann Institute of Science, IL-76100 Rehovot, Israel
}

(Dated: J. Phys. Chem. A MS jp0369589: Received October 2, 2003; Accepted November 14, 2003)

\begin{abstract}
Anharmonic force fields and vibrational spectra of the azabenzene series (pyridine, pyridazine, pyrimidine, pyrazine, s-triazine, 1,2,3-triazine, 1,2,4-triazine and s-tetrazine) and benzene are obtained using density functional theory (DFT) with the B97-1 exchange-correlation functional and a triple-zeta plus double polarization (TZ2P) basis set. Overall, the fundamental frequencies computed by second-order rovibrational perturbation theory are in excellent agreement with experiment. The resolution of the presently calculated anharmonic spectra is such that they represent an extremely useful tool for the assignment and interpretation of the experimental spectra, especially where resonances are involved.
\end{abstract}




\section{INTRODUCTION}

For atomization energies and geometries, density functional theory (DFT) constitutes a cost-effective alternative to wavefunction-based $a b$ initio methods, being capable of accuracies on the order of a few $\mathrm{kcal} / \mathrm{mol}$ and a few picometer, respectively, if basis sets of polarized triple zeta quality are employed 1, 2].

As a result of this astonishing success, especially considering the modest computational cost of DFT methods, a variety of new applications are now being explored [3, 4, 5, 6, 7], including, very recently, the calculation of molecular anharmonic potential energy surfaces 8]. Anharmonic potential energy surfaces (see Refs. 9, 10] for initial pioneering studies at the SCF and CISD level) allow for the prediction of molecular vibration-rotation spectra that can be compared directly to experiment, obviating the need to make estimations or approximations for the effect of anharmonicity. $\operatorname{CCSD}(\mathrm{T}) / s p d f$ anharmonic force fields can achieve accuracies on the order of $10 \mathrm{~cm}^{-1}$ or better for fundamentals (e.g. [11] and references therein), and even greater accuracy is achievable if still larger basis sets and corrections for inner-shell correlation are considered $[12,13]$.

DFT anharmonic force fields for small molecules have recently been the subject of two validation studies [14, 15]. Our own validation study 15] suggested that, for fundamental frequencies, an RMS accuracy of about $18 \mathrm{~cm}^{-1}$ can be attained when using the B97-1 functional with sufficiently large basis sets. The question arises as to how capable DFT is to treat medium-sized organic molecules in this fashion. Particularly relevant here is the study the study of Miani et al.[16] on the fundamental frequencies of benzene, which employed the B3LYP 17, 18] functional with the TZ2P (triple-zeta plus double polarization) basis set. This paper, as well as a more recent study of furan, pyrrole and thiophene 19], in fact yielded even more accurate results on these medium-sized organic systems than suggested by the small-molecule validation studies cited above.

The azabenzenes are obtained by systematically replacing $\mathrm{CH}$ moieties in benzene by nitrogen atoms. Numerous experimental spectra of these compounds are available in the literature, ranging from mono-azabenzene (pyridine) to 1,2,4,5-tetraazabenzene (s-tetrazine). Pentazine is quite elusive [20]; the equally elusive $\mathrm{N}_{6}$ (hexazine or hexaazabenzene) molecule has been the subject of extensive theoretical studies [21, 22]: at the CCSD(T)/cc-pVTZ level, the hexazine (hexaazabenzene) structure undergoes distortion 
from the idealized $D_{6 h}$ ring to a $D_{2}$ geometry, which is a local minimum situated some 23 $\mathrm{kcal} / \mathrm{mol}$ above the $C_{2 h}$ diazide global minimum[22]. Straka recently made the interesting suggestion that cyclic $\mathrm{N}_{6}$ may form very stable $\mathrm{M}\left(\eta^{6}-\mathrm{N}_{6}\right)$ complexes with $\mathrm{M}=\mathrm{Ti}, \mathrm{Zr}$, Hf, $\operatorname{Th}[23]$.

In practice, nine molecules are relevant to the present study: the parent benzene molecule, pyridine, pyridazine, pyrimidine, pyrazine, 1,2,3-triazine, 1,2,4-triazine, 1,2,5triazine (sym-triazine) and 1,2,4,5-tetrazine (s-tetrazine). All molecules are displayed in figure 1 .

Azabenzene skeletons serve as building blocks in nature, e.g., pyridine in pyridixol (vitamin $\mathrm{B}_{6}$ ), pyridazine and pyrimidine in pteridine, itself found in folic acid (vitamin vitamin $\mathrm{B}_{10}$ ) and riboflavin (vitamin $\mathrm{B}_{2}$ ). Moreover the four DNA bases are derivates of pyrimidine $(\mathrm{C}, \mathrm{T})$ and of purine $(\mathrm{A}, \mathrm{G})$ - itself a pyrimidine-imidazole fused ring system. For these reasons, azabenzene-like compounds figure in drug design, e.g. the reverse transcriptase inhibitors AZT (contains pyrimidine) or nevirapine (contains pyridine). Derivatives of pyridazine have been found to have potential therapeutic or plant growth inhibitory effects. Quite different applications include melamine-based plastics (melamine is a derivative of s-triazine) and the potential use of s-tetrazine in molecular data storage applications (one of the relaxation mechanisms of the $S_{1}$ state leads to $2 \mathrm{HCN}+\mathrm{N}_{2} \cdot[24$, 25, 26, 27, 28]).

Innes, Ross and Moomaw (IRM throughout this paper) published a compilation and critical review of experimental vibration spectroscopic data current to 1988 29]. One of us (with C. Van Alsenoy) carried out a harmonic-only B3LYP/cc-pVTZ study of the vibrational frequencies and geometries. [30] The limitations of this approach are obvious.

In the present contribution, we will consider DFT anharmonic force fields and anharmonic vibrational spectra — which are directly comparable to experiment — for the azabenzenes, and demonstrate their power as a spectroscopic assignment tool for medium-sized organic molecules.

\section{COMPUTATIONAL DETAILS}

In our validation study[15], we considered a wide variety of exchange-correlation functionals, as well as convergence in terms of the basis set and the integration grids (both 
Kohn-Sham, KS, and Coupled Perturbed Kohn-Sham).

Especially for organic molecules, we found the best performance to be delivered by the B97-1 functional, which is Handy's reparametrization 31] of Becke's 1997 hybrid functional [32]. Satisfactory basis set convergence was generally found to be achieved with the TZ2P basis set [33]. This is therefore the functional/basis set combination employed for the present study.

We found [15] results for anharmonic force field calculations to be exceedingly dependent on the KS integration grid, much less so on the CPKS grid. For the present study, we ended up using a $(200,974)$ grid, that is, the direct product of a 200-point Euler-MacLaurin radial grid with a 974-point Lebedev angular grid. For the CPKS steps, we employed a $(75,194)$ grid, which considerably reduced the overall computational cost. Neither grid was pruned.

The quartic force fields were calculated by numerical central differences (in rectilinear normal coordinates) of analytical second derivatives, using a stand-alone driver program adapted from the CADPAC electronic structure program system [34]. The actual DFT second derivative calculations were done using the Gaussian 98 Rev. A11 program package[35].

The step size in a numerical derivatives calculation always represents a compromise between discretization error and roundoff error. Based on experience, we determined the step size as a functions of both the absolute value of the harmonic frequency associated with

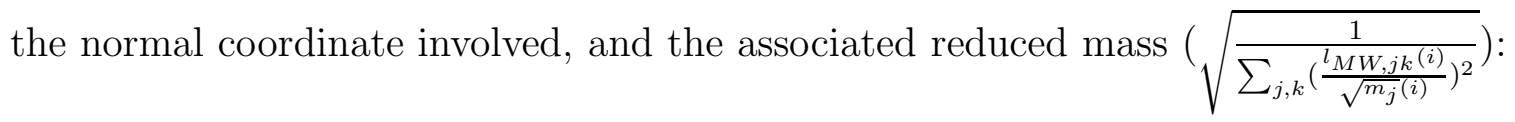

$$
q_{s t e p}(i)=4 \times \sqrt{\frac{1}{\sum_{j, k}\left(\frac{l_{M W, j k}(i)}{\sqrt{m_{j}}(i)}\right)^{2}}} \times \sqrt{\frac{1000}{\omega(i)}}
$$

In order to reduce roundoff error as much as possible, the KS and CPKS equations were basically converged to machine precision.

To calculate this factor, both the reduced mass of the mode $m_{j}$ and the eigenvalues of the normalisation matrix $l_{M W, j k}$ are needed. The last part of equation 1, depending on the harmonic frequencies $\omega$, additionally ensures that each displaced geometry has approximately the same energy difference to the minimum geometry.

In this manner, we obtain a complete cubic force field, as well as all the diagonal and semidiagonal quartic force constants. These are sufficient for second-order rovibrational perturbation theory analyses [36, 37, 38, 39, 40], which were carried out using the 
SPECTRO [41] and POLYAD [42] programs developed in the Cambridge group and at

Weizmann, respectively.

\section{RESULTS AND DISCUSSION}

\section{A. Benzene}

The parent molecule of our series, benzene (Figure 1a), has been the subject of a few previous anharmonic force field studies, two at the SCF/DZP level 43, 44], and a very recent one at the B3LYP/TZ2P level[16]. An extensive experimental literature exists on the subject (see Refs. 16, 45] for reviews): high resolution data are available for many of the fundamentals, and all the assignments can be regarded as conclusive. (An analysis of the B3LYP/cc-pVTZ normal modes of benzene and the azabenzenes in terms of Pulay's redundant internal coordinates can be found in Table 17 of Ref. [30].)

Experimentally obtaining harmonic frequencies for a molecule this large, even with such high symmetry, is a nearly impossible task. In Table @ we compare computed harmonic frequencies with selected prior calculations (in particular $\operatorname{CCSD}(\mathrm{T}) / \operatorname{spdf}$ data [46]), as well as several sets of experimentally derived data. The first such set are the ' $\omega_{a v}$ ' estimates of Handy, Murray and Amos (HMA) 47], themselves obtained as averages of an empirical estimate by Goodman, Ozkabak, and Thakur (GOT) [45] and their own combination of experimental fundamentals with the SCF/DZP computed anharmonicities of Maslen et al. 43]. The second set are derived from the experimental fundamentals and a new SCF/DZP anharmonic analysis by Handy and Willetts (HW) [44]. The third set is derived from the experimental fundamentals and the B3LYP/TZ2P anharmonicities [16], and is expected to be the most reliable.

Both sets of DFT numbers compare about equally well with the CCSD(T) data. The C-H stretching frequencies are underestimated by about $20 \mathrm{~cm}^{-1}$, while all other frequencies are being reproduced very accurately. (As an aside, we note that the $\mathrm{C}-\mathrm{H}$ underestimation problem also occurs 48] at the Møller-Plesset perturbation theory (MP2) level.) Although the $\mathrm{C}-\mathrm{H}$ stretches are reproduced marginally worse by the $\mathrm{B} 97-1$ functional $\left(3 \mathrm{~cm}^{-1}\right)$ compared to the reference $\operatorname{CCSD}(\mathrm{T}) / s p d f$ values, the overall performance is improved: the mean absolute error decreases from 9.3 (B3LYP) to $6.5(\mathrm{~B} 97-1) \mathrm{cm}^{-1}$, and the RMS deviation 
from 10.6 (B3LYP) to 9.6 (B97-1). The smaller decrease for the RMS error (compared to the mean absolute error) can be attributed to the greater proportional weight given to larger errors. When excluding the $\mathrm{C}-\mathrm{H}$ stretching frequencies, the RMS errors decrease to 8.4 (B3LYP) and $4.3 \mathrm{~cm}^{-1}$ (B97-1). Considering the computational cost of density functional theory, the B3LYP results are already of spectacular compared to the reference ab initio data. The B97-1 functional, however, reduces the RMS error of the non C-H stretching frequencies by an additional $50 \%$.

Both functionals yield excellent agreement with experiment for the fundamental frequencies (Table II). The experimental data were taken from the earlier compilation of GOT [45] and from more recent gas-phase measurements[16]. The two sets of experimental data agree very well with each other, except for $\nu_{16}$ and $\nu_{12}$ which are involved in strong Fermi resonances. To obtain the B97-1/TZ2P fundamentals, we had to take the following Fermi resonances into consideration: $\nu_{3}+\nu_{16}$ and $\nu_{15}$ (with the deperturbed frequency $\nu_{15}$ at $3018 \mathrm{~cm}^{-1}$ and the combination at $2947 \mathrm{~cm}^{-1}$ ), $\nu_{13}+\nu_{16}$ and $\nu_{12}$ (unperturbed $\nu_{20}$ at 3040 and the combination band at $3082 \mathrm{~cm}^{-1}$ ), $\nu_{16}+\nu_{13}$ and $\nu_{5}$ (with the unperturbed frequencies at 3064 and 3020 $\mathrm{cm}^{-1}$ ), and $\nu_{2}+\nu_{18}$ and $\nu_{16}$ (with $\nu_{16}$ (unperturbed) at 1600, $\nu_{2}+\nu_{18}$ at $1603 \mathrm{~cm}^{-1}$ ).

Interestingly, because of the small differences in the harmonic frequencies between the B3LYP/TZ2P and the B97-1/TZ2P calculations and the different force field, now new Fermi resonances are predicted. Furthermore, the fundamentals affected by these resonances are the ones which differ the most when using the B3LYP or B97-1 functional. Because of the Fermi resonances, the difference between different functionals and methods becomes more important than on the harmonic level of approximation. The results of both functionals compared to experiment are, however, very similar, with mean absolute errors (compared to the latest experimental results of Miani et al. 16]) of 9.4 (B3LYP) and $8.3(\mathrm{~B} 97-1) \mathrm{cm}^{-1}$ and RMS errors of 17.0 and $13.7 \mathrm{~cm}^{-1}$, respectively. Again, all frequencies are very well described with the exception of the $\mathrm{C}-\mathrm{H}$ stretches, which are underestimated by $16-30 \mathrm{~cm}^{-1}$ (discounting $\nu_{5}$ which is severely perturbed by resonances). Without the $\mathrm{C}-\mathrm{H}$ stretches, the mean absolute errors are reduced to 3.7 (B3LYP) and $3.9(\mathrm{~B} 97-1) \mathrm{cm}^{-1}$ and the RMS errors to 4.8 (B3LYP) and $4.5 \mathrm{~cm}^{-1}$ (B97-1). Hence, while clearly better for harmonic frequencies, the B97-1 functional is only slightly better for predicting the fundamental frequencies of benzene. Nevertheless, the accuracy obtained by density functional theory, which yields RMS errors of less than $5 \mathrm{~cm}^{-1}$ for non $\mathrm{C}-\mathrm{H}$ stretching frequencies, is very good. 
In the third column, we added the B97-1/TZ2P anharmonic corrections to the CCSD(T)/ANO4321 harmonic frequencies of Ref.[46], in order to see how such a 'hybrid' ab initio-DFT approach would perform. The principal improvement seen is for the $\mathrm{C}-$ $\mathrm{H}$ stretches, which are thus all bought into the range of the experimental values, except for $\nu_{5}$, which is in resonance with $\nu_{16}+\nu_{13}$ as discussed above. When discounting $\mathrm{C}-\mathrm{H}$ stretching frequencies, the improvement compared to a pure B97-1/TZ2P calculation is quite modest, to $3.1 \mathrm{~cm}^{-1}$ for the mean absolute error and to $4.1 \mathrm{~cm}^{-1}$ for the RMS error. The corresponding error statistics including $\mathrm{C}-\mathrm{H}$ stretching frequencies change rather more significantly, to a mean absolute error of $4.0 \mathrm{~cm}^{-1}$ and an RMS error of $7.4 \mathrm{~cm}^{-1}$. Summarizing, B97-1/TZ2P is likely to be a useful tool for analysis of vibrational spectra (and verification of their assignments) of aromatic organic molecules in general and of the azabenzene series in particular.

\section{B. Pyridine}

Pyridine being the simplest azabenzene (Figure 1b) and the closest to the parent molecule, we may anticipate similar accuracy as for benzene. As expected for this chemically important species, many experimental spectra are available, in both liquid and gas phases. Most of the

experimental results and the latest experimental assignments are summarized by Klots 49]. The computed and observed vibrational frequencies are presented in Table III. As expected, the $\mathrm{C}-\mathrm{H}$ stretching frequencies are not well described. Here, they are also heavily perturbed, and, considering performance for the corresponding bands in benzene, our method may not be sufficiently accurate to assist in the experimental assignment. Thus, although we will attempt to elaborate on the $\mathrm{C}-\mathrm{H}$ stretching frequencies for most azabenzenes, the results are more tentative. Additionally, a small change in the original unperturbed fundamental frequencies will cause large changes in the perturbed frequencies. Nevertheless, the two asymmetric stretches $\nu_{14}$ and $\nu_{15}$ do not follow the general trend of being underestimated by $20-40 \mathrm{~cm}^{-1}$. While the perturbed $\nu_{14}$ is close to the experimental value, $\nu_{15}$ differs by $70 \mathrm{~cm}^{-1}$. Especially the latter appears too large to be accounted for merely by deficiencies in our DFT calculation. Here, the severe Fermi resonance seems to be responsible for this assignment, as its deperturbed value is at $3021 \mathrm{~cm}^{-1}$. This mode is resonating with (deperturbed frequencies given) $\nu_{14}$ at $3053 \mathrm{~cm}^{-1}, \nu_{4}+\nu_{17}$ at $3015 \mathrm{~cm}^{-1}$ and $\nu_{16}+\nu_{5}$ at 
$3054 \mathrm{~cm}^{-1}$, with the perturbed $\nu_{4}+\nu_{17}$ now appearing at $3023 \mathrm{~cm}^{-1}$. It appears that the latter value is more in line with experiment, and that perhaps this assignment might be more reasonable. Nevertheless, some caution is appropriate as the $\mathrm{C}-\mathrm{H}$ harmonic stretching frequencies are not as well described by DFT as the remaining modes. Large basis set $\operatorname{CCSD}(\mathrm{T})$ harmonic frequencies would be helpful here, but would require inordinate amounts of CPU time.

Another picture emerges for the non $\mathrm{C}-\mathrm{H}$ frequency modes. Here, we primarily compare to the medium resolution Raman vapor data of Klots (Klots2) [49]: their assignments seem to be in line with most other experiments, although they differ from the most recent data obtained by Partal et al. 50]. Comparing to these latter inelastic neutron scattering (INS) data, however, amounts to comparing apples and oranges, as the INS data are based on further refinement of a DFT computed harmonic force field by maximizing agreement between simulated and observed INS spectral. The pseudo-harmonic frequencies from the refined force field correspond neither to true harmonic nor to true fundamental frequencies — in effect, they are neither fish nor fowl.

We can confirm the assignment of Klots [49] of $\nu_{21}$ to the lower value of $1053 \mathrm{~cm}^{-1}$. Difficult assignments seem to result from the Fermi resonances for both $\nu_{4}$ and $\nu_{19}$, since these are the only fundamentals which give errors of $10 \mathrm{~cm}^{-1}$ or larger. The deperturbed mode of $\nu_{4}$ at $1578 \mathrm{~cm}^{-1}$ resonates with $\nu_{9}+\nu_{10}$ at $1593 \mathrm{~cm}^{-1}$ resulting in perturbed modes at 1575 and $1596 \mathrm{~cm}^{-1}$. Klots may have misassigned the latter band to $\nu_{4}$ rather than $\nu_{9}+\nu_{10} . \nu_{19}$, on the other hand, seems to be very difficult to assign from experimental data because of its depolarized character. The problem is further exacerbated as $\nu_{19}$ is located at the shoulder of $\nu_{6}$. Although $\nu_{19}$ is involved in a Fermi resonance, it is probably not the source of the disagreement with, since its unperturbed frequency at $1241 \mathrm{~cm}^{-1}$ resonates with $\nu_{10}+\nu_{12}$ at $1282 \mathrm{~cm}^{-1}$, resulting in bands at 1237 and $1289 \mathrm{~cm}^{-1}$. With the exception of these two strongly perturbed bands $\left(\nu_{4}\right.$ and $\left.\nu_{19}\right)$, the agreement between experiment and theory can only be described as stunning for bands other than C-H stretches. For the latter, probably only a full $\operatorname{CCSD}(\mathrm{T})$ force field can resolve the assignment. Even when including $\nu_{4}$ and $\nu_{19}$ (but excluding all $\mathrm{C}-\mathrm{H}$ stretching frequencies), the mean absolute error for the computed values compared to the experimental data of Klots [49] is $3.6 \mathrm{~cm}^{-1}$ and the RMS error is 5.3 $\mathrm{cm}^{-1}$; without $\nu_{4}$ and $\nu_{19}$ they are reduced to 2.7 and $3.8 \mathrm{~cm}^{-1}$, respectively.

The double-harmonic infrared intensities are in good agreement with the B3LYP/cc-pVTZ 
values [30] and in reasonable agreement with the experimental numbers. Even here, the C-H stretches differ, probably not only because of anharmonic contributions and Fermi resonances, but also because of the poor description of these modes by DFT. Still, the excellent performance seen for benzene results is repeated for pyridine.

\section{Pyridazine}

Pyridazine (Figure 1c) has been of particular interest in the last couple of years [51, 52, 53]. A large body of experimental data is available, generally measured in the gas phase but when certain modes were unavailable, the authors of Ref. 52, 53] substituted their own liquid or solid phase measurements in order to get a full complement of frequencies. All of the spectra have been assigned with the aid of scaled Hartree-Fock, MP2, BLYP or B3LYP harmonic force fields using small basis sets. Some of them have their force fields fitted to match the experimental data. Despite the large amount of data, huge discrepancies exist, as shown in Table IV. This seems to be especially true for the out-of-plane modes where experimental assignments and values seem almost arbitrary. For $\nu_{11}$, for example, the experimental numbers range from 765 to $949 \mathrm{~cm}^{-1}$, and even the two most recent numbers appear at opposite ends of this range. These assignments have been done using different methods and scaling techniques, since no reliable theoretical data were available at the time. The same problem with the $\mathrm{C}-\mathrm{H}$ stretches that was encountered for benzene and pyridine occurs for pyridazine as well; the situation is further complicated since the experimental data differs and thus we cannot assign the frequencies of the experiment. Despite the discrepancies between various experimental numbers, all the $\mathrm{C}-\mathrm{H}$ stretches appear plausible within the error range of our method.

As the INS data set dramatically varies from the remainder of the experimental data, and because it did not appear to be reliable for pyridine, it was excluded from our analysis, although it is reported in Table IV for completeness.

Since such a large amount of experimental data is available, it is best to discuss each mode separately, starting with the in-plane modes.

- For $\nu_{3}$, all experiments except the first of Ref. [54] agree on an assignment to the 1570 $\mathrm{cm}^{-1}$ band. Our results, however, would seem to indicate that the assignment around $1555 \mathrm{~cm}^{-1}$ might be more plausible. 
- The same occurs for $\nu_{4}$. Experimental values of Refs. [53, 54] cluster around 1440 $\mathrm{cm}^{-1}$, with Refs. [52, 55] around $1415 \mathrm{~cm}^{-1}$. Our calculation clearly favors the former assignment.

- For $\nu_{5}$, significant differences between experiments of Refs. [52, 54, 55] and the computed value of $1145 \mathrm{~cm}^{-1}$ can be found. The experimental results are thus untenable in light of this huge discrepancy of more than a hundred $\mathrm{cm}^{-1}$, and only Ref.[55] proposes an assignment of $1160 \mathrm{~cm}^{-1}$, which still appears to be on the high side.

- For $\nu_{6}$, most experiments have assignments around the computed $1157 \mathrm{~cm}^{-1}$; however, Ref. [53] assigned this mode to $1120 \mathrm{~cm}^{-1}$ because of their previous assignment. Our calculated $\nu_{5}$ and $\nu_{6}$ nearly coincide,

- For $\nu_{7}$, all experimental datasets are in agreement with each other and our calculations. Considering the generally small anharmonicities for this type of vibrations, the discrepancy of $40 \mathrm{~cm}^{-1}$ between the computed $\omega_{8}$ and the observed $\nu_{8}$ seems to be a bit on the large side. The experimental assignment may have been complicated by the band's position in an IR band envelope going from 960 to $980 \mathrm{~cm}^{-1}[53]$.

- As with $\nu_{5}$, the experimental assignment for $\nu_{9}$ of Vazquez et al. [53] differs from the other obtained fundamentals, and is the only one that can be confirmed by our calculations.

- For $\nu_{16}$, only Refs. [52, 54] differ from the computed values, while for $\nu_{17}$, the experimental assignment of Stidham and Tucci 55] both in the IR and the Raman phase appear doubtful. $\nu_{18}$ agrees nicely with all experiments.

- For $\nu_{19}$ and $\nu_{20}$, the same assignment problems that we experienced for $\nu_{5}$ and $\nu_{6}$ seem to have occurred; while most experiments assign values above $1100 \mathrm{~cm}^{-1}$ to $\nu_{19}$, only Vazquez et al. [53] seem to give the correct assignment. This results, however, in the value of $\nu_{20}$ thus ending up a bit on the low side, and only the value of Ref. [55] ends up close to our calculated number. The same seems to have happened to $\nu_{21}$, where only Ref. [53] is in line with our calculations. Hence, for the in-plane modes, the data set of 
Vazquez et al. [53] appears to be most reliable, excluding $\nu_{3}$ and $\nu_{6}$ (which appear to be dubious assignments) and perhaps $\nu_{8}$ and $\nu_{20}$.

- For the out-of-plane modes, the experimental assignment appears to be even more problematic. For $\nu_{22}$, all experiments differ by $20 \mathrm{~cm}^{-1}$, and are either found at 998 or $842 \mathrm{~cm}^{-1}$. Both assignments appear to be unlikely, since the harmonic B97-1 frequency is at $981 \mathrm{~cm}^{-1}$, which would put the fundamental too low for 998 and definitely way too high for assignment to the $842 \mathrm{~cm}^{-1}$ band.

- For $\nu_{23}$, all experimental assignments are around the computed $751 \mathrm{~cm}^{-1}$, while for $\nu_{24}$, all the experiments appear to yield assignments higher than our computed fundamental of $362 \mathrm{~cm}^{-1}$.

- Based on our data, all the $a_{2}$ symmetry modes $\left(\nu_{10}\right.$ through $\left.\nu_{13}\right)$ should probably be re-examined, since several experimental results differ drastically from each other and from our calculations. A discussion of these modes is almost impossible, and with the exception of Refs. [53, 54] for $\nu_{13}$, all experimental assignments lie beyond the likely error bars of the theoretical values.

On the whole, the pyridazine vibrational spectra definitely merit further investigation, as the many experimental and theoretical datasets available are considerably at variance with each other. Thus, it is impossible to give an error estimate for the method used based on this molecule. However if our computational results prove to be as accurate as for benzene and pyridine, the experimental spectra have to be reexamined. Based on this study, one might wonder whether the addition of more nitrogens or the $\mathrm{N}-\mathrm{N}$ bond is causing the deterioration of the calculated values.

\section{Pyrimidine}

Pyrimidine (Figure 1d), has been studied less in recent years. Notable are the IR experiments compiled by IRM[29], the IR experiments of Billes et al.[52], and the inelastic neutron scattering work of Navarro et al. [56]. Here, we compare mainly to the IR experiments, since the INS data for neither pyridine nor pyridazine agree well with our computed values and the other experiments, for reasons outlined above. Nevertheless, 
for pyrimidine the INS data seem a lot closer to the IR data than for the previous two azabenzenes (Table $\nabla$ ). The values for the $a_{1} \mathrm{C}-\mathrm{H}$ stretches are in agreement with experiment, although this seems fortuitous. Otherwise, all in-plane modes are within 8 $\mathrm{cm}^{-1}$ of experiment, with the sole exception of $\nu_{17}$. Interestingly, both $\nu_{7}$ and $\nu_{9}$ undergo strong Fermi type 1 and 2 resonances; their resonance matrices are displayed in TabldVI with their respective eigensolutions. For $\nu_{7}$, very small changes in the unperturbed fundamentals would result in the value ending up not at $1071 \mathrm{~cm}^{-1}$, but at the experimental assignment of $1065 \mathrm{~cm}^{-1}$. The assignment of the two resonating modes appears to be purely arbitrary. As for $\nu_{9}$, the resonating overtone of $\nu_{24}$ matches the experimental number exactly. Since both modes are in resonance, the overtone might have "borrowed intensity" (as described in Ref. [57]) from $\nu_{9}$, and thus the assignment.

When looking at the out-of-plane modes in Table $\mathbf{V}$, only $\nu_{10}$ and $\nu_{20}$ yield different results compared to the first set of experimental results. Both discrepancies have been mentioned before by the harmonic-only study 30$]$, and $\nu_{20}$ has a very small intensity. Moreover, by using scaled HF frequencies, Wiberg[58] has suggested that the assignment for $\nu_{10}$ might also be incorrect. The IRM [29] assignments for modes 5, 6, 13 and 21 appear more plausible than from Ref.[52]. Neglecting the problematic modes 10 and 20 and reassigning mode 9 to $677 \mathrm{~cm}^{-1}$, the errors, including the $\mathrm{C}-\mathrm{H}$ stretches, are 6.3 (mean absolute) and 11.4 $\mathrm{cm}^{-1}$ (RMS), and without them are 4.1 and $5.3 \mathrm{~cm}^{-1}$, respectively. Thus this method again appears to be very reliable for predicting fundamental frequencies.

\section{E. Pyrazine}

As with pyrimidine, only few experiments have been done for pyrazine (Figure 1e). The vibrational assignments are displayed in Table VII] In Ref. [52], assignments were done in the gas phase for the IR active modes and in a melt for the Raman spectrum. Overall, the agreement is again very good for modes other than $\mathrm{C}-\mathrm{H}$ stretches. If the previously mentioned tendency to underestimate the $\mathrm{C}-\mathrm{H}$ stretches is taken into account,

all assignments appear plausible, with the possible exception of the assignment of $\nu_{11}$ from Ref.[52]. It should be noted that all of the $\mathrm{C}-\mathrm{H}$ stretches are perturbed by Fermi resonances. For the in-plane modes, especially $\nu_{21}$ appears to lie beyond the error bars of our method. It has been mentioned by the harmonic-only study in Ref.[30] that this 'Kekulé mode' is 
problematic and it was concluded that this mode has significant multireference character, since it corresponds to the dissociation into $2 \mathrm{HCN}+\mathrm{C}_{2} \mathrm{H}_{2}$. However, hybrid density functionals are usually capable to describe nondynamical correlation to a certain extent, since for example the atomization energy of ozone is reasonably well reproduced. For this mode, the assignment of Ref. [59] appears to be out of question.

For all the other modes, most the experiments scatter only by about $5 \mathrm{~cm}^{-1}$, with this agreement suggesting that their assignments and values are pretty accurate. The out-of-plane modes are generally quite well described by theory. Note that the two $a_{u}$ modes since they are neither IR nor Raman active; for this reason they are not assigned in Ref. [52]. The INS values are somewhat disappointing for both frequencies, since the chief advantage of this method is the ability to predict such bands. Another discrepancy is the first $b_{2 g}$ mode $\left(\nu_{9}\right)$, although the second experiment of Ref.[52] is closer to our values.

This leads to mean absolute and RMS errors compared to Ref.[52] (Ref.[59]) of 7.8 (7.9) and $10.4(11.1) \mathrm{cm}^{-1}$ including the $\mathrm{C}-\mathrm{H}$ stretches, and of $5.4(5.1)$ and $6.9(6.5) \mathrm{cm}^{-1}$ when excluding them. If the problematic $\nu_{2}$ and $\nu_{9}$ are excluded, the mean absolute and RMS errors for the non C-H stretches reduces to 4.1 (4.1) and $5.4(5.5) \mathrm{cm}^{-1}$, respectively. Thus, the general RMS discrepancy of 5 to $7 \mathrm{~cm}^{-1}$ is obtained for pyrazine as well.

\section{F. 1,3,5 Triazine (s-Triazine)}

1,3,5-Triazine (Figure 1f) is the only azabenzene with a degenerate point group symmetry $\left(D_{3 h}\right)$. Because of this, the $a_{2}^{\prime}$ modes $\left(\nu_{4}\right.$ and $\left.\nu_{5}\right)$ are both IR and Raman inactive. The INS 60] value for _nu $u_{4}$ coincides exactly with our calculation (Table VIII); the discrepancy of $124 \mathrm{~cm}^{-1}$ for $\nu_{5}$ is outlandish even for the INS data and this band is probably misassigned. The inelastic neutron scattering data [50, 51, 56, 60, 61] are clearly inferior to the other experimental datasets. This is hardly surprising as this method relies on fitting and scaling a harmonic force field which is obtained from DFT in small split-valence basis sets. Already for the harmonics, this introduces errors on the order of about $50 \mathrm{~cm}^{-1}$. The error for the $\mathrm{C}-\mathrm{H}$ stretches is expected to be even larger. It would be interesting to reanalyze their data based on the present anharmonic force fields, although this still would not resolve the problems associated with the $\mathrm{C}-\mathrm{H}$ stretches, for which large basis set coupled cluster 
frequencies would be desirable. The experimental IR/Raman data of Daunt et al. 62] and Lancaster et al. 63] are very similar to those of IRM 29] and are not listed in Table [III] With the exception of the first $e^{\prime \prime} \nu_{12}$ and the $\mathrm{C}-\mathrm{H}$ stretches, which are again underestimated, all computed values are within $11 \mathrm{~cm}^{-1}$ of experiment Again, the errors are similar to the other azabenzenes; including the $\mathrm{C}-\mathrm{H}$ stretches, the mean absolute error is $7.6 \mathrm{~cm}^{-1}$ and the RMS error $11 \mathrm{~cm}^{-1}$. Excluding the stretches (and $\nu_{12}$ ), these numbers reduce to $5.1(3.4$ ) and $7.5(5.0) \mathrm{cm}^{-1}$, respectively.

\section{G. 1,2,3-Triazine}

For 1,2,3-Triazine (Figure 1g), only one IR and Raman spectrum in $\mathrm{KBr}$ has been experimentally determined [64]: the assignment was assisted by scaled $M P 2 / 6-31 G^{*}$ harmonic frequencies. The spectrum looks very similar to that of pyrimidine; even the same Fermi resonances are present.

At first glance at the spectra in Table IX] the agreement between theory and experiment is disappointing. For very few of the modes is there agreement between the spectra. However, the authors did not consider any Fermi resonances in the lower spectrum (although they noted that one might exist, involving $\nu_{17}$ ), and simply assumed the ordering of the fundamentals to be identical to that of the $\mathrm{MP} 2 / 6-31 \mathrm{G}^{*}$ harmonics. This however leads to obvious misassignments. For example, $\nu_{6}$ and $\nu_{18}$ lie almost on top of each other, while $\nu_{12}+\nu_{13}$ borrows intensity from $\nu_{6}$ because of the Fermi resonance, as can be seen in Table X] If the resonance were not as strong as computed - specifically, if the unperturbed fundamental were shifted only a few $\mathrm{cm}^{-1}$ towards higher values, the perturbed $\nu_{12}+\nu_{13}$, presently calculated at $1056 \mathrm{~cm}^{-1}$, might easily correspond to the band at $1064 \mathrm{~cm}^{-1}$, assigned to $\nu_{6}$ in Ref. [64]. The same actually applies to $\nu_{20}$, which has a strong Fermi resonance with $\nu_{9}+\nu_{13}$, that has, however, been calculated at a lower value of $644 \mathrm{~cm}^{-1}$. We have also reassigned the first $a_{1} \mathrm{C}-\mathrm{H}$ stretch (mode 1), since the discrepancy between experiment and theory appears too high even for a C-H stretch. Needless to say, this mode also has a strong Fermi resonance with the $2 \nu_{15}$ overtone, which has its largest component for the eigenvector with associated eigenvalue at at $3100 \mathrm{~cm}^{-1}$, again explaining the experimental value perfectly. The only other value which is still in question would be a small peak at $1597 \mathrm{~cm}^{-1}$, which might correspond to an impurity; a band was found that 
was assigned to acetylene, a fragmentation product of 1,2,3-triazine. The value of $318 \mathrm{~cm}^{-1}$, which has been reported for $\nu_{13}$ is actually just a scaled Hartree-Fock harmonic frequency. Therefore, a dramatic change in the errors is obtained by reassigning the experimental spectrum. Including the $\mathrm{C}-\mathrm{H}$ stretches in the error analysis, the mean absolute error decreases from 17.7 to $4.7 \mathrm{~cm}^{-1}$ and the RMS error from 27.9 to $6.1 \mathrm{~cm}^{-1}$. By excluding the $\mathrm{C}-\mathrm{H}$ stretches, the mean absolute and RMS errors improve from 14.6 and $22.1 \mathrm{~cm}^{-1}$, respectively, to 4.1 and $5.2 \mathrm{~cm}^{-1}$. Thus, accuracy consistent with the preceding azabenzenes can be obtained following some reassignments in the experimental spectrum. This also corroborates our conclusion concerning pyridazine that neither substitution of $\mathrm{C}-\mathrm{H}$ by $\mathrm{N}$ nor $\mathrm{N}-\mathrm{N}$ bonds seem to be responsible for the discrepancies between experimental and computed vibrational spectra.

\section{H. 1,2,4-Triazine}

Because 1,2,4-triazine (Figure 1h) is highly unstable, only one "full" experimental spectrum has been measured as a liquid film [65], although more recently two high-resolution IR spectra have been recorded for four frequencies [66, 67]. For the C-H stretches (Table XI), possibly $\nu_{1}$ and $\nu_{2}$ may have been swapped, since they both take part in a large resonance matrix block. Overall, ten frequencies and combination bands interact forming this large resonance block that include modes 1 to 3 . Hence, it is not surprising that a correct assignment based merely on experimental data would be problematic. With this swap, all three $\mathrm{C}-\mathrm{H}$ stretches are underestimated by the usual $10-30 \mathrm{~cm}^{-1}$. Only $\nu_{11}$ appears questionable in view of our results. However, $\nu_{9}$ has a Fermi resonance with the combination of $\nu_{17}$ and $\nu_{21}$, and the resonance, eigenvector and eigenvalue matrices are displayed in Table XII. The Fermi resonances displayed in these tables are similar to pyrimidine, 1,2,3-triazine and 1,2,4-triazine. Assuming that both of the Fermi resonances are slightly stronger than predicted, since $\nu_{21}$ is underestimated by $3 \mathrm{~cm}^{-1}$ compared to the high-resolution IR data, the new $\nu_{17}+\nu_{21}$ could well end up lower than the predicted $1143 \mathrm{~cm}^{-1}$, explaining the value of $1136 \mathrm{~cm}^{-1}$ that would then not be assigned to any mode. The assignment of $\nu_{11}$ in the experiment would then correspond to $\nu_{10}$, in agreement with the calculated spectrum. The assignment of $\nu_{13}$ also appears to be incorrect.

Of the four modes obtained by high-resolution IR, the newer data for $\nu_{12}$ validates our 
computational value of $1044 \mathrm{~cm}^{-1}$ rather than the $1050 \mathrm{~cm}^{-1}$ predicted by the older experiment. On the other hand, the low-resolution IR value of $769 \mathrm{~cm}^{-1}$ for mode 19 is closer to the hi-res data compared to our predicted $779 \mathrm{~cm}^{-1}$. These new experiments show the usefulness of the theoretical value, since its resolution is apparently even comparable to that obtained by low-resolution IR data.

Without making any reassignments to the experimental spectrum, the mean absolute error from experiment is $13.6 \mathrm{~cm}^{-1}$, and the RMS error is $19.2 \mathrm{~cm}^{-1}$ including the $\mathrm{C}-\mathrm{H}$ stretches. This appears to be quite large in comparison to the other azabenzenes. With the abovementioned suggested reassignments, these errors change to $7.5 \mathrm{~cm}^{-1}$ and $10.0 \mathrm{~cm}^{-1}$, respectively. Excluding the $\mathrm{C}-\mathrm{H}$ stretches, we once again end up with a mean absolute error of $5.1 \mathrm{~cm}^{-1}$ and an RMS error of $5.8 \mathrm{~cm}^{-1}$.

\section{1,2,4,5-Tetrazine (s- Tetrazine)}

For 1,2,4,5-Tetrazine (Figure 1i), $\operatorname{CCSD}(\mathrm{T})$ harmonic frequencies are available in the literature [25]. Unfortunately, they were calculated with all electrons correlated in a basis set $\left(6-311 \mathrm{G}^{* *}\right)$ that is only minimal in the inner-shell orbitals. The resulting errors in harmonic frequencies can easily exceed $20 \mathrm{~cm}^{-1}$ for small molecules [68], several times larger than the actual effect of neglecting core correlation (typically less than $10 \mathrm{~cm}^{-1}$ in $\mathrm{HCNOF}$ systems [69]). We have recomputed the $\operatorname{CCSD}(\mathrm{T}) / 6-311 \mathrm{G}^{* *}$ frequencies correlating only valence electrons (Table XIII). For the in-plane modes, differences with the all-electron calculations are quite minor $\left(6 \mathrm{~cm}^{-1}\right.$ or less). The out-of-plane modes, however, are drastically affected, up to $60 \mathrm{~cm}^{-1}$ (Table XIII, especially the $a_{u}$ and the second $\mathrm{b}_{3 u}$ frequencies). This adds yet another stanza to the long litany of rejoinders in the literature (e.g. [70]) against the practice of correlating inner-shell electrons in basis sets unsuitable for the purpose.

We have recalculated the harmonic frequencies at the $\operatorname{CCSD}(\mathrm{T})$ level (frozen core) with basis sets of spdf quality, specifically Dunning's popular cc-pVTZ [71] and the Almlöf-Taylor atomic natural orbital 72] basis set used in Ref. 46] for benzene. The CCSD(T)/cc-pVTZ and $\operatorname{CCSD}(\mathrm{T}) / \mathrm{ANO} 4321$ frequencies (Table XIII) are in excellent agreement with each other, the largest difference being $6 \mathrm{~cm}^{-1}$ for the lowest frequency $\left(\omega_{18}\right)$. (This is very unlike the case of benzene[46], where the two $b_{2 g}$ modes are hypersensitive to the basis set and 
differ significantly even between cc-pVTZ and ANO4321.) . The two corresponding modes in s-tetrazine display appreciable differences between 6-311G* and cc-pVTZ but barely between cc-pVTZ and ANO4321.) In contrast, the $\operatorname{CCSD}(\mathrm{T}) / 6-311 \mathrm{G}^{* *}$ frequencies differs significantly from both data sets, particularly for the two $b_{2 g}$ modes $\left(39\right.$ and $33 \mathrm{~cm}^{-1}$ w.r.t. ANO4321), followed by the lowest $b_{2 u}$ mode (a.k.a. 'Kekulé mode', $27 \mathrm{~cm}^{-1}$ ) and the $a_{u}$ mode $\left(25 \mathrm{~cm}^{-1}\right.$, but a relative error of $\left.7 \%\right)$. So even for a valence-only CCSD(T) calculation, the 6-311G** basis set is insufficient, and the RMS deviation from the CCSD(T)/ANO4321 results, $16.4 \mathrm{~cm}^{-1}$ (17.3 when excluding the $\mathrm{C}-\mathrm{H}$ stretching frequencies), is comparable to that of the much more cost-effective B97-1 calculations, $18.1(15.1) \mathrm{cm}^{-1}$.

Turning now to the B97-1/TZ2P harmonic frequencies, the most notable differences with the $\mathrm{CCSD}(\mathrm{T}) / \mathrm{ANO} 4321$ data are for the $\mathrm{CH}$ stretches (underestimates of $34 \mathrm{~cm}-1$ for both) and the Kekulé mode (overestimated by $37 \mathrm{~cm}-1$ ). Possibly, self-interaction error would adversely affect 73] the presently used functional's description of the potential surface along the Kekulé mode, and it would be interesting how a self-interaction corrected functional would perform. Unfortunately no implementation of such a functional is available to the authors, let alone an implementation including analytical derivatives. Exclusive of this mode and the $\mathrm{CH}$ stretches, the RMS deviation between the CCSD(T)/ANO4321 and B97-1/TZ2P frequencies is about $11 \mathrm{~cm}^{-1}$, compared to just $4 \mathrm{~cm}^{-1}$ for benzene.

As expect, agreement between B97-1/TZ2P fundamentals and experiment is likewise compromised (Table XIV]). We note that s-tetrazine is both the least stable and the most 'inorganic' molecule of the series, and that it has a low-lying excited state at less than 2 $\mathrm{eV}$ [25]. If we combine the $\mathrm{CCSD}(\mathrm{T}) / \mathrm{ANO} 4321$ harmonic frequencies with the B97-1/TZ2P anharmonic corrections, the picture brightens somewhat. Compared to the assignment of IRM 29], the RMS deviation amounts to $9.8 \mathrm{~cm}^{-1}$ if the symmetric $\mathrm{C}-\mathrm{H}$ stretch is excluded. The peculiarly large splitting of $76 \mathrm{~cm}^{-1}$ between IRM's symmetric and asymmetric $\mathrm{CH}$ stretches is impossible to reconcile with any of our calculations, all of which suggest a very small splitting on the order of just $3 \mathrm{~cm}^{-1}$, in agreement with the earlier film IR and Raman study of Sigworth and Pace (SP) [74]. (Their band origin of $3089 \mathrm{~cm}^{-1}$ for the symmetric CH stretch is quite compatible with our calculations: IRM's value of $3010 \mathrm{~cm}^{-1}$ was taken from single-vibronic-level fluorescence spectra [5]. An older gas-phase study by Franks, Merer, and Innes (FMI) 76] found both $\mathrm{CH}$ stretches at $3090 \mathrm{~cm}^{-1}$; the symmetric one in the IR, the antisymmetric one in the Raman spectrum.) Our calculations do not reveal a resonance 
interaction affecting $\nu_{1}$ that is severe enough to make a large $\mathrm{CH}$ symmetric/antisymmetric spllitting plausible. We hence conclude that $\nu_{1}$ of IRM is erroneous.

One other IRM assignment which is difficult to reconcile with our best calculations concerns the highest $b_{3 u}$ mode (calculated: 902, IRM: $929 \mathrm{~cm}^{-1}$ ) for which the Franks, Merer, and Innes [6] value of $904 \mathrm{~cm}^{-1}$ nearly perfectly matches our calculation. It would appear that even the somewhat degraded performance, exhibited by our model for this molecule, still ought to be quite useful for resolving assignment issues or guiding highresolution spectroscopic measurements.

\section{CONCLUSIONS}

We have assessed the performance of modern density functional theory (particularly, B97-1/TZ2P) for the anharmonic vibrational spectra of a series of related medium-sized molecules. The C-H stretching frequencies are consistently underestimated by about 20-30 $\mathrm{cm}^{-1}$; disregarding them, the level of agreement with experiment that can be achieved is quite astonishing (on the order of $6 \mathrm{~cm}^{-1} \mathrm{RMS}$ deviation for fundamentals). Somewhat poorer accuracy is achieved for pyridazine and particularly for s-tetrazine. For several systems (particularly 1,2,3-triazine), our calculations strongly suggest revised assignments of the observed frequencies. For pyridazine, unfortunately, the experimental results are mutually contradictory and our analysis inconclusive. For s-tetrazine, basically all predicted fundamentals agree less well with experiment; the more 'inorganic' character of the molecule may have adversely affected the performance of our calculations. Nevertheless, even here a RMS deviation of about $15 \mathrm{~cm}^{-1}$ for DFT and $10 \mathrm{~cm}^{-1}$ for the combined CCSD(T)/DFT results is obtained.

Overall, B97-1/TZ2P quartic force fields combined with second-order rovibrational perturbation theory shows great promise for the assignment of vibrational spectra of medium-sized organic molecules.

\section{ACKNOWLEDGMENTS}

A. D. Boese is grateful for financial support from the Feinberg Graduate School. This research was supported by the Lise Meitner-Minerva Center for Computational Quantum 
Chemistry, of which J. M. L. Martin is a member, and the Helen and Martin A. Kimmel Center for Molecular Design.

\section{Supporting information}

B97-1/TZ2P quartic force fields in normal coordinates of the molecules studied are available for download (in SPECTRO format) at the URL http://theochem.weizmann.ac.il/web/papers/azabenzenes.html.

[1] Boese, A. D.; Handy, N. C.; J. Chem. Phys. 1145497 (2001).

[2] Boese, A. D.; Martin, J. M. L.; Handy, N. C.; J. Chem. Phys. 2003, 119, 3005.

[3] Colwell, S. M.; Handy, N. C.; Lee, A. M.; Phys. Rev. A 1996, 53, 1316.

[4] Jamorski, C.; Casida, M. E.; Salahub, D. R.; J. Chem. Phys. 1996, 104, 5134.

[5] Bauernschmitt, R.; Ahlrichs, R.; Chem. Phys. Lett. 1996, 256, 454.

[6] van Caille, C.; Amos, R. D.; Chem. Phys. Lett. 2000, 317, 159.

[7] Amos, R. D.; Chem. Phys. Lett. 2002, 364, 612.

[8] Dressler, S.; Thiel, W.;Chem. Phys. Lett. 1997, $273,71$.

[9] Clabo Jr., D. A.; Allen, W. D.; Remington, R. B.; Yamaguchi, Y.; Schaefer III, H. F.; Chem. Phys. 1988, 123, 117.

[10] Allen, W. D.; Yamaguchi, Y.; A. G. Császár, Clabo, D. A.; Remington, R. B.; Schaefer III, H. F.; Chem. Phys. 1990, 145, 427.

[11] Martin, J. M. L.; Lee, T. J.; Taylor, P. R.; François, J. P.; J. Chem. Phys. 1995, 103, 2589.

[12] Martin, J. M. L.; Lee, T. J.; and Taylor, P. R.; J. Chem. Phys. 1998, 108, 676.

[13] Martin, J. M. L.; Chem. Phys. Lett. 1998, 292, 411.

[14] Neugebauer, J.; Hess, B. A.; J. Chem. Phys. 2003, 118, 7215.

[15] Boese, A. D.; Martin, J. M. L.; submitted.

[16] Miani, A.; Cane, E.; Palmieri, P.; Trombetti, A.; Handy, N. C.; J. Chem. Phys. 2000, 112, 248.

[17] Becke, A. D.; J. Chem. Phys. 1993, 98, 5648. 
[18] Lee, C.; Yang, W.; Parr, R. G.; Phys. Rev. B 37, 785 (1988)

[19] Burcl, R.; Handy, N. C.; Carter, S.;Spectrochim. Acta A 2003, 59, 1881.

[20] Politzer, P.; Murray, J. S.; Seminario, J. M.; Miller, R. S.; J. Mol. Struct. (THEOCHEM) 1992, 94, 155 .

[21] Saxe, P.; Schaefer III, H. F.; J. Am. Chem. Soc. 1983, 105, 1760.

[22] Tobita, M.; Bartlett, R. J.; J. Phys. Chem. A 2001, 105, 4107 and references therein; see also http://www.qtp.ufl.edu/ ${ }^{\sim}$ bartlett/downloads/polynitrogen.pdf.

[23] Straka, M.; Chem. Phys. Lett. 2002, 358, 531.

[24] Scheiner, A. C.; Schaefer III, H. F.; J. Chem. Phys. 1987, 87, 3539

[25] M. Schütz, Hutter, J.; Lüthi, H. P.; J. Chem. Phys. 1995, 103, 7048.

[26] Stanton, J. F.; and Gauss, J.; J. Chem. Phys. 1996, 104, 9859.

[27] Rubio, M.; Roos, B. O.; Mol. Phys. 1999, 96, 603.

[28] Nooijen, M.; J. Phys. Chem. A 2000, 104, 4553.

[29] Innes, K. K.; Ross, I. G.; Moomaw, W. R.; J. Mol. Spectrosc. 1988, 132, 492.

[30] Martin, J. M. L.; Van Alsenoy, C.; J. Phys. Chem. 1996, 100, 6973.

[31] Hamprecht, F. A.; Cohen, A. J.; Tozer, D. J.; and Handy, N. C.; J. Chem. Phys. 1998, 109, 6264 .

[32] Becke, A. D.; J. Chem. Phys. 1997, 107, 8554

[33] Dunning, T. H.; J. Chem. Phys. 1971, 55, 716.

[34] The Cambridge Analytic Derivatives Package (CADPAC), Issue 6.5, Cambridge, 1998; developed by Amos, R. D., with contributions from Alberts, I. L.; Andrews, J. S.; Colwell, S. M.; Handy, N. C.; Jayatikala, D.; Knowles, P.J.; Kobayashi, R.;Laidig, K. E.; Laming, G.; Lee, A. M.; Maslen, P. E.; Murray, C. W.; Palmieri, P.; Rice, J. E.; Simandiras, E. D.; Stone, A. J.; Su, M.-D.; Tozer, D. J.

[35] Frisch, M.J.; Trucks, G.W.; Schlegel, H.B.; Scuseria, G.E.; Robb, M.A.; Cheeseman, J.R.; Zakrzewski, V.G.; J.A. Montgomery Jr., Stratmann, R. E.; Burant, J. C.; Dapprich, S.; Millam, J. M.; Daniels, A.D.; Kudin, K.N.; Strain, M.C.; Farkas, O.; Tomasi, J.; Barone, V.; Cossi, M.; Cammi, R.; Mennucci, B.; Pomelli, C.; Adamo, C.; Clifford, S.; Ochterski, J.; Petersson, G.A.; Ayala, P.Y.; Cui, Q.; Morokuma, K.; Malick, D.K.; Rabuckm, A.D.; Raghavachari, K.; Foresman, J.B.; Cioslowski, J.; Ortiz, J.V.; Baboul, A.G.; Stefanov, B.B.; Liu, G.; Liashenko, A.; Piskorz, P.; Komaromi, I.; Gomperts, R.; Martin, R.L.; Fox, D.J.; 
Keith, T.; M.A. Al-Laham, Peng, C.Y.; Nanayakkara, A.; Gonzalez, C.; Challacombe, M.; Gill, P.M.W.; Johnson, B.; Chen, W.; Wong, M.W.; Andres, J.L.; Gonzalez, C.; M. Head-Gordon, Replogle, E.S.; and Pople, J.A.; Gaussian 98, Revision A. 11 (Gaussian, Inc., Pittsburgh, PA, 1998).

[36] Mills, I. M.; in: Molecular Spectroscopy: Modern Research, eds. K. Narahari Rao, C. W. Mathews, Vol. 1, Academic Press, New York 1972, pp. 115-140.

[37] D. A. Clabo Jr., Allen, W. D.; Remington, R. B.; Yamaguchi, Y.; Schaefer III, H. F.; Chem. Phys. 1988, 123, 187.

[38] Allen, W. D.; Yamaguchi, Y.; Csaszar, A. G.; Clabo, D. A.; Remington, R. B.; Schaefer III, H. F.; Chem. Phys. 1990, 145, 427.

[39] Schneider, W.; and Thiel, W.; Chem. Phys. Lett. 1989, 157, 367.

[40] Hoy, A. R.; Mills, I. M.; and Strey, G.; Mol. Phys. 1972, 24, 1265.

[41] Gaw, J. F.; Willets, A.; Green, W. H.; Handy, N. C.; In Advances in Molecular Vibration and Collision Dynamics; Bowman, J. M., Ed.; JAI: Grennwich, CT, 1990.

[42] Martin, J. M. L.; "POLYAD: a vibrational perturbation theory program including arbitrary resonance matrices" (Weizmann Institute of Science, Rehovot, 1997).

[43] Maslen, P. E.; Handy, N. C.; Amos, R. D.; Jayatilaka, D.; J. Chem. Phys. 1992, 97, 4233.

[44] Handy, N. C.; Willets, A.; Spectrochim. Acta A 1997, 53, 1169.

[45] Goodman, L.; Ozkabak, A. G.; Thakur, S. N.; J. Phys. Chem. 1991, 95, 9044.

[46] Martin, J. M. L.; Taylor, P. R.; and Lee, T. J.; Chem. Phys. Lett. 1997, 275, 414.

[47] Handy, N. C.; Murray, C. W.; and Amos, R. D.; J. Phys. Chem. 1993, 97, 4392.

[48] Handy, N. C.; Maslen, P. E.; Amos, R. D.; Andrews, J. S.; Murray, C. W.; and Laming, G. J.; Chem. Phys. Lett. 1992, 197, 506.

[49] Klots, T. D.; Spectrochim. Acta A 1998, 54, 1481.

[50] Partal, F.; Fernandez Gomez, M.; Lopez Gonzalez, J. J.; Navarro, A.; Kearley, G. H.; Chem. Phys. 2000, 261, 239.

[51] Navarro, A.; Vazquez, J.; Montejo, M.; Lopez Gonzalez, J. J.; Kearley, G. J.; Chem. Phys. Lett. 2002, 361, 483.

[52] Billes, F.; Mikosch, H.; and Holly, S.; J. Mol. Struct. (THEOCHEM) 1998, 423, 225.

[53] Vazquez, J.; Lopez Gozalez, J. J.; Marquez, F.; Boggs, J. E.; J. Raman Spectrosc. 1998, 29, 547. 
[54] Ozono, Y.; Nibu, Y.; Shimada, H.; and Shimada, R.; Bull. Chem. Soc. Jpn. 1986, 59, 2997.

[55] Stidham, H. D.; and Tucci, J. V.; Spectrochim. Acta A 1967, 23, 2233.

[56] Navarro, A.; Fernandez Gomez, M.; Lopez Gonzalez, J. J.; Fernandez Liencres, M. P.; Martinez Torres, E. M.; Tomkinson, J.; Kearley, G. J.; J. Phys. Chem. A 1999, 103, 5833.

[57] Burcl, R.; Carter, S.; and Handy, N. C.; Chem. Phys. Lett. 2003, 380, 237.

[58] Wiberg, K. B.; J. Mol. Struct. 1990, $244,61$.

[59] Arenas, J. F.; Lopez Navarrete, J. T.; Otero, J. C.; Marcos, J. I.; J. Chem. Soc. Faraday Trans. 2 1985, 81, 405.

[60] Navarro, A.; Lopez Gonzalez, J. J.; Kearley, G. J.; Tomkinson, J.; Parker, S. F.; and Sivia, D. S.; Chem. Phys. 1995, 200, 395.

[61] Kearley, G. J.; Tomkinson, J.; Navarro, A.; Lopez Gonzalez, J. J.; Fernandez Gomez, M.; Chem. Phys. 1997, 216, 323.

[62] Daunt, S. J.; Shurvell, H. F.; J. Mol. Spectrosc. 1976, 62, 373.

[63] Lancaster, J. E.; Stamm, R. F.; Colthup, N. B.; Spectrochim. Acta 1961, 17, 155.

[64] Fischer, G.; Nwankwoala, A. U.; Olliff, M. P.; Scott, A. P.; J. Mol. Spectrosc. 1993, 161, 388.

[65] Neunhoffer, H.; Hennig, H.; Chemische Berichte 1968, 101, 3952.

[66] Palmer, M. H.; Maier, R. R. J.; Hegelund, F.; Newnham, D. A.; J. Mol. Spectrosc. 1998, 192, 331.

[67] Hegelund, F.; Larsen, R. W.; Nelander, B.; Christen, D.; Palmer, M. H.; J. Mol. Spectrosc. 2003, 217, 9 .

[68] Martin, J. M. L.; Schwenke, D. W.; Lee, T. J.; Taylor, P. R.; J. Chem. Phys. 1996, $104,4657$.

[69] Martin, J. M. L.; Chem. Phys. Lett. 1995, 242, 343.

[70] Little can be added to this statement: "Using valence-optimized basis sets and including corecorrelation is not only a waste of computer time, but a potential source of problems, as it can substantially increase BSSE. This point is not well appreciated: the prevailing view appears to be that no harm can come of correlating the core when the basis set is inadequate. This is not so." (Taylor, P. R.; In Lecture Notes in Quantum Chemistry; Roos, B. O., Ed.; Springer: Berling, 1992; p. 406).

[71] Dunning Jr., T. H.; J. Chem. Phys. 90, 1007 (1989)

[72] Almlöf, J.; Taylor, P. R.; J. Chem. Phys. 86, 4070 (1987)

[73] Patchkovskii, S.; Ziegler, T.; J. Chem. Phys. 116, 7806 (2002) 
[74] Sigworth, W. D.; Pace, E. L.; Spectrochim. Acta A 1971, 27, 747

[75] Brumbaugh, D. V.; Innes, K. K.; Chem. Phys. 1981, 59, 413.

[76] Franks, L. A.; Merer, A. J.; Innes, K. K.; J. Mol. Spectrosc. 1968, 26, 458.

[77] DiLella, D. P.; and Stidham, H. D.; J. Raman Spectrosc. 1980, 9, 90.

[78] Wiberg, K. B.; Walters, V. A.; Colson, S. D.; J. Phys. Chem. 1984, 88, 6067; Wong, K. N.; Colson, S. D.; J. Mol. Spectrosc. 1984, 104, 129; Walters, V. A.; Snavely, D. A.; Colson, D. A.; Wiberg, K. B.; Wong, K. N.; J. Phys. Chem. 1986, 90, 592.

[79] Kakiuti, Y.; Akiyama, M.; Saito, N.; Saito, H.; J. Mol. Spectrosc. 1976, 61, 164.

[80] Califano, S.; Crawford Jr., B. Spectrochim. Acta 1960, 16, 900.

[81] Vibrational Spectra of Polyatomic Molecules Sverdlov, L. M.; Kovner, M. A.; Krainov, E. P., Eds.; J. Wiley and Sons: New York, Toronto, 1974; p. 533 ff. 
<smiles>[14CH3]c1ccccc1</smiles>

(a) pyridine<smiles>c1ccccc1</smiles>

(b)<smiles>O=[Pt]c1ccccc1</smiles>

(c)

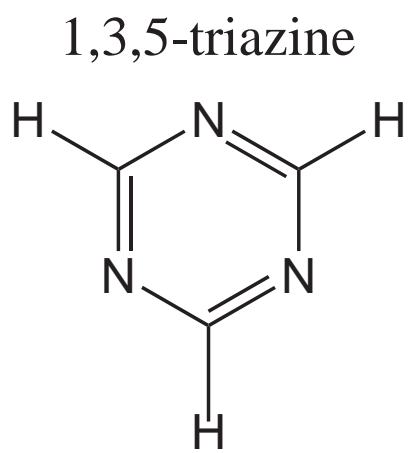

(f) pyrimidine<smiles>c1cncnc1</smiles>

(d)<smiles>[123IH]c1cccnn1</smiles>

(g)

1,2,4,5-tetrazine

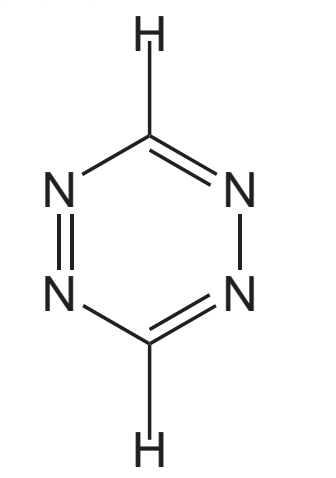

(i) pyrazine<smiles>c1ccncc1</smiles>

(e)<smiles>[Y10][14CH2]c1cccnn1</smiles>

(h)

FIG. 1: Boese et al., Journal of Physical Chemistry A 
Fig. 1:

The molecules investigated in this study, including benzene and the azabenzene series up to 1,2,4,5-tetrazine. 
TABLE I: Harmonic frequencies of benzene.

\begin{tabular}{|c|c|c|c|c|c|c|}
\hline & \multicolumn{3}{|c|}{ Calculated } & \multicolumn{3}{|c|}{ Derived from Experiment } \\
\hline & B97-1 & B3LYP 16$]$ & $\operatorname{CCSD}(\mathrm{T})[46]$ & $\operatorname{HMA}^{a}[47]$ & $\mathrm{HW}^{b}[44]$ & $\mathrm{MCPTH}^{d}[16]$ \\
\hline \multicolumn{7}{|c|}{ In-Plane } \\
\hline $\mathrm{a}_{1 g}$ & 3189 & 3192 & 3210 & 3198 & 3191 & 3218 \\
\hline & 1008 & 1012 & 1003 & 1001 & 1008 & 1003 \\
\hline $\mathrm{a}_{2 g}$ & 1380 & 1392 & 1380 & 1378 & 1367 & 1392 \\
\hline \multirow[t]{2}{*}{$\mathrm{b}_{2 g}$} & 1012 & 1017 & 1009 & 1000 & 990 & 1012 \\
\hline & 718 & 723 & 709 & 712 & 718 & 717 \\
\hline \multirow[t]{4}{*}{$\mathrm{e}_{2 g}$} & 3165 & 3168 & 3183 & 3182 & 3174 & 3210 \\
\hline & 1628 & 1635 & 1637 & 1623 & 1607 & 1645 \\
\hline & 1195 & 1201 & 1194 & 1185 & 1178 & 1197 \\
\hline & 617 & 624 & 611 & 610 & 613 & 617 \\
\hline $\mathrm{e}_{1 g}$ & 863 & 864 & 865 & 856 & 847 & 861 \\
\hline$a_{2 u}$ & 686 & 686 & 687 & 680 & 686 & 683 \\
\hline \multirow[t]{2}{*}{$\mathrm{b}_{1 u}$} & 3155 & 3159 & 3173 & 3173 & 3174 & \\
\hline & 1022 & 1031 & 1020 & 1016 & 1024 & 1030 \\
\hline \multicolumn{7}{|c|}{ Out-of-Plane } \\
\hline $\mathrm{b}_{2 u}$ & 1330 & 1333 & 1326 & 1313 & 1318 & 1338 \\
\hline & 1170 & 1178 & 1163 & 1158 & 1167 & 1163 \\
\hline $\mathrm{e}_{2 u}$ & 987 & 992 & 985 & 978 & 967 & 987 \\
\hline & 408 & 412 & 406 & 402 & 1058 & 1056 \\
\hline $\mathrm{e}_{1 u}$ & 3180 & 3183 & 3200 & 3186 & 3181 & 3212 \\
\hline & 1509 & 1519 & 1509 & 1503 & 1494 & 1522 \\
\hline & 1055 & 1060 & 1056 & 1048 & 1058 & 1057 \\
\hline
\end{tabular}

${ }^{a} \omega_{a v}$ Handy, Murray and Amos, based on the experiments of Goodman et al.[45].

${ }^{b}$ Handy and Willets, experimental $\nu_{i}$ (Goodman et al.[45]) - HF $\left(\nu_{i}-\omega_{i}\right)$.

${ }^{b}$ Miani, Cane, Palmieri, Trombetti, and Handy, experimental $\nu_{i}-\operatorname{B3LYP} / \mathrm{TZ2P}\left(\nu_{i}-\omega_{i}\right)$. 
TABLE II: Computed and observed fundamental frequencies of benzene. For the deviations experiment-theory, values in parentheses are exclusive of $\mathrm{C}-\mathrm{H}$ stretching frequencies.

\begin{tabular}{|c|c|c|c|c|c|c|}
\hline & & \multicolumn{3}{|c|}{ Calculated } & \multicolumn{2}{|c|}{ Experiment } \\
\hline & Mode & B97-1/TZ2P & B3LYP/TZ2P & $\operatorname{CCSD}(\mathrm{T}) / \mathrm{B} 97-1$ & GOT[45] & $\mathrm{MCP}[16]$ \\
\hline \multicolumn{7}{|c|}{ In-Plane } \\
\hline \multirow[t]{2}{*}{$\mathrm{a}_{1 g}$} & 1 & 3048 & 3051 & 3069 & 3074 & 3073 \\
\hline & 2 & 992 & 995 & 987 & 993 & 993 \\
\hline $\mathrm{a}_{2 g}$ & 3 & 1348 & $1351^{*}$ & 1348 & 1350 & 1350 \\
\hline \multirow[t]{2}{*}{$\mathrm{b}_{2 g}$} & 7 & 987 & 997 & 984 & 990 & 993 \\
\hline & 8 & 707 & 708 & 698 & 707 & 702 \\
\hline \multirow[t]{4}{*}{$\mathrm{e}_{2 g}$} & 15 & $3032^{*}$ & 3028 & 3050 & 3057 & 3057 \\
\hline & 16 & $1611^{*}$ & $1613^{*}$ & 1620 & 1601 & 1610 \\
\hline & 17 & 1178 & 1181 & 1177 & 1178 & 1178 \\
\hline & 18 & 613 & $615^{*}$ & 607 & 608 & 608 \\
\hline $\mathrm{e}_{1 g}$ & 11 & 841 & 846 & 843 & 847 & 847 \\
\hline $\mathrm{a}_{2 u}$ & 4 & 672 & 677 & 673 & 674 & 674 \\
\hline \multirow[t]{2}{*}{$\mathrm{b}_{1 u}$} & 5 & $3004^{*}$ & $2988^{*}$ & 3022 & 3057 & 3057 \\
\hline & 6 & 1006 & 1015 & 1004 & 1010 & 1014 \\
\hline \multicolumn{7}{|c|}{ Out-of-Plane } \\
\hline \multirow[t]{2}{*}{$\mathrm{b}_{2 u}$} & 9 & 1309 & 1305 & 1305 & 1309 & 1309 \\
\hline & 10 & 1156 & 1163 & 1149 & 1150 & 1148 \\
\hline \multirow[t]{2}{*}{$\mathrm{e}_{2 u}$} & 19 & 964 & 972 & 962 & 967 & 968 \\
\hline & 20 & 400 & 403 & 398 & 398 & 398 \\
\hline \multirow[t]{3}{*}{$\mathrm{e}_{1 u}$} & 12 & $3031^{*}$ & $3023^{*}$ & 3051 & 3064 & 3048 \\
\hline & 13 & 1486 & 1484 & 1486 & 1484 & 1484 \\
\hline & 14 & 1045 & 1038 & 1046 & 1038 & 1038 \\
\hline & B3LYP & \multicolumn{3}{|c|}{ RMS deviation experiment-theory } & $15.2(4.2)$ & $17.0(4.8)$ \\
\hline & B97-1 & \multicolumn{3}{|c|}{ RMS deviation experiment-theory } & $12.2(2.8)$ & $13.7(4.5)$ \\
\hline \multicolumn{2}{|c|}{$\mathrm{CCSD}(\mathrm{T}) / \mathrm{B} 97-1$} & \multicolumn{3}{|c|}{ RMS deviation experiment-theory } & $7.8(4.5)$ & $7.4(4.1)$ \\
\hline
\end{tabular}

* Band affected by Fermi resonance. 
TABLE III: Computed and observed fundamental frequencies of pyridine (infrared intensities in $\mathrm{km} / \mathrm{mol}$ for IR active modes are given in parentheses). All RMS deviations exclude C-H stretches.

\begin{tabular}{|c|c|c|c|c|c|c|c|c|c|c|}
\hline & \multirow[b]{3}{*}{ Mode } & \multicolumn{3}{|c|}{ Calculated } & \multicolumn{6}{|c|}{ Experiment } \\
\hline & & \multirow{2}{*}{\begin{tabular}{|l|} 
B3LYP/pVTZ \\
Harmonic[30] \\
\end{tabular}} & \multicolumn{2}{|c|}{ B97-1/TZ2P } & \multicolumn{2}{|r|}{ IR } & \multicolumn{3}{|c|}{ Raman } & \multirow{2}{*}{\begin{tabular}{|l} 
INS \\
Refined
\end{tabular}} \\
\hline & & & Harmonic & Fundamental & Liquid & Vapor & Vapor & Liquid & Solution & \\
\hline & Mode & Ref.[30] & \multicolumn{2}{|c|}{ this work } & Ref.[77] & Ref.[78] & Klots[49] & Klots[49] & Ref.[79] & Ref.[50] \\
\hline \multicolumn{11}{|c|}{ In-Plane } \\
\hline \multirow[t]{10}{*}{$a_{1}$} & 1 & $3195(7.4)$ & $3191(4.4)$ & $3054^{*}$ & 3070 & $3094(0.0)$ & 3094 & 3090 & & 3089 \\
\hline & 2 & $3171(5.2)$ & $3168(4.0)$ & $3043^{*}$ & 3057 & $3073(1.5 \pm 1.0)$ & 3067 & 3056 & & 3075 \\
\hline & 3 & $3147(6.8)$ & $3147(3.5)$ & $3012^{*}$ & 3025 & $3030(8.5 \pm 1.0)$ & 3030 & 3021 & & 3057 \\
\hline & 4 & $1626(23.8)$ & $1620(23.3)$ & $1575^{*}$ & 1581 & $1584(17.9 \pm 1.8)$ & 1590 & 1588 & & 1582 \\
\hline & 5 & $1518(3.2)$ & $1512(3.4)$ & 1483 & 1483 & $1483(4.0 \pm 0.4)$ & 1483 & 1482 & & 1482 \\
\hline & 6 & $1244(3.2)$ & $1240(3.5)$ & 1221 & 1217 & $1218(4.3 \pm 0.4)$ & 1218 & 1217 & & 1209 \\
\hline & 7 & $1096(3.0)$ & 1091(3.6) & 1071 & 1069 & $1072(4.5 \pm 0.5)$ & 1072 & 1068 & & 1058 \\
\hline & 8 & $1052(7.7)$ & $1044(6.8)$ & 1028 & 1030 & $1032(7.7 \pm 0.8)$ & 1032 & 1031 & & 1030 \\
\hline & 9 & $1012(5.7)$ & $1006(4.9)$ & 990 & 991 & $991(5.4 \pm 0.5)$ & 991 & 991 & & 991 \\
\hline & 10 & $617(4.7)$ & $610(4.1)$ & 604 & 603 & $601(4.4 \pm 0.4)$ & 601 & 603 & & 603 \\
\hline \multirow[t]{9}{*}{$\mathrm{b}_{2}$} & 14 & $3186(26.7)$ & $3183(17.3)$ & $3090^{*}$ & 3079 & $3094(15.9 \pm 1.6)$ & 3087 & 3079 & & 3034 \\
\hline & 15 & $3144(29.9)$ & $3145(20.7)$ & $2971^{*}$ & 3034 & $3042(5.1 \pm 1.5)$ & 3042 & 3035 & & 3018 \\
\hline & 16 & $1621(8.9)$ & $1614(8.3)$ & 1575 & 1574 & $1581(7.3 \pm 1.8)$ & 1581 & 1573 & & 1580 \\
\hline & 17 & $1477(27.2)$ & $1468(28.0)$ & 1442 & 1437 & $1442(31.1 \pm 3.1)$ & 1442 & 1438 & & 1437 \\
\hline & 18 & $1391(0.1)$ & $1384(0.1)$ & 1356 & 1355 & $1362(0.5 \pm 0.2)$ & 1355 & 1355 & & 1355 \\
\hline & 19 & $1283(0.07)$ & $1280(0.0)$ & $1237^{*}$ & 1227 & $1227(0.0)$ & 1225 & 1228 & & 1230 \\
\hline & 20 & $1173(2.4)$ & $1166(2.5)$ & 1155 & 1146 & $1143(3.6 \pm 0.4)$ & 1143 & 1147 & & 1137 \\
\hline & 21 & $1080(0.1)$ & $1073(0.01)$ & 1045 & 1069 & $1079(0.0)$ & 1052 & 1053 & & 1045 \\
\hline & 22 & $670(0.2)$ & $664(0.3)$ & 658 & 654 & $652(1.1 \pm 0.2)$ & 654 & 653 & & 654 \\
\hline \multicolumn{11}{|c|}{ Out-of-Plane } \\
\hline \multirow[t]{5}{*}{$\mathrm{b}_{1}$} & 23 & $1023(0.02)$ & 1012(0.02) & 993 & 1007 & $1007(0.0)$ & 991 & 995 & 988 & 1005 \\
\hline & 24 & $964(0.01)$ & $957(0.04)$ & 940 & 941 & $937(0.0)$ & 937 & 941 & 931 & 948 \\
\hline & 25 & $769(5.9)$ & $761(9.9)$ & 749 & 747 & $744(12.9 \pm 1.3)$ & 744 & 749 & 744 & 748 \\
\hline & 26 & $721(63.1)$ & $715(69.4)$ & 704 & 703 & $700(67.5 \pm 6.7)$ & 700 & 708 & 700 & 710 \\
\hline & 27 & $422(3.5)$ & $414(3.5)$ & 406 & 406 & $403(7.2)$ & 403 & 407 & 405 & 406 \\
\hline \multirow[t]{3}{*}{$a_{2}$} & 11 & 1011 & 1003 & 980 & 980 & 966 & 982 & 982 & 979 & 984 \\
\hline & 12 & 899 & 895 & 877 & 884 & 871 & 875 & 884 & 873 & 895 \\
\hline & 13 & 385 & 379 & 371 & 380 & 373 & 371 & 379 & 374 & 380 \\
\hline \multicolumn{2}{|c|}{ B97-1 } & \multicolumn{3}{|c|}{ RMS deviation experiment-theory } & 6.5 & 8.4 & 5.3 & 5.2 & & \\
\hline
\end{tabular}

* Band affected by Fermi resonance. 
TABLE IV: Computed and observed fundamental frequencies of pyridazine.

\begin{tabular}{|c|c|c|c|c|c|c|c|c|c|c|}
\hline & & \multirow{2}{*}{\multicolumn{2}{|c|}{$\frac{\text { Calculated }}{\text { B97-1/TZ2P }}$}} & \multicolumn{7}{|c|}{ Experiment } \\
\hline \multirow{2}{*}{\multicolumn{2}{|c|}{ Mode }} & & & \multicolumn{3}{|c|}{ IR } & \multicolumn{3}{|c|}{ Raman } & \multirow{2}{*}{\begin{tabular}{|l} 
INS \\
Ref. [51
\end{tabular}} \\
\hline & & Harmonic & Fundamental & Ref.[55] & Ref. [54] & Ref.[52] & Ref. [53] & Ref.[55] & Ref.[54] & \\
\hline \multicolumn{11}{|c|}{ In-Plane } \\
\hline \multirow[t]{9}{*}{$a_{1}$} & 1 & 3193 & $3061^{*}$ & 3068 & & 3082 & 3086 & 3064 & 3070 & 3086 \\
\hline & 2 & 3166 & $3034^{*}$ & 3056 & & 3052 & 3071 & 3052 & 3053 & 3071 \\
\hline & 3 & 1604 & 1558 & 1570 & 1555 & 1568 & 1570 & 1572 & 1570 & 1547 \\
\hline & 4 & 1477 & 1446 & 1415 & 1440 & 1418 & 1444 & 1417 & 1441 & 1465 \\
\hline & 5 & 1180 & 1145 & & 1340 & 1337 & 1160 & 1347 & 1352 & 1188 \\
\hline & 6 & 1171 & 1157 & 1159 & 1153 & 1154 & 1119 & 1160 & 1150 & 1177 \\
\hline & 7 & 1088 & 1064 & 1061 & 1055 & 1061 & 1061 & 1063 & 1063 & 1075 \\
\hline & 8 & 1006 & 987 & 963 & 960 & 969 & 968 & 964 & 963 & 998 \\
\hline & 9 & 676 & 669 & 629 & 622 & 622 & 668 & 630 & 632 & 670 \\
\hline \multirow[t]{8}{*}{$b_{2}$} & 14 & 3180 & $3056^{*}$ & 3085 & & 3082 & 3079 & 3083 & 3080 & 3079 \\
\hline & 15 & 3162 & $3052^{*}$ & 3056 & & 3080 & 3057 & 3052 & 3041 & 3057 \\
\hline & 16 & 1601 & 1556 & 1563 & 1540 & 1572 & 1563 & 1566 & 1564 & 1571 \\
\hline & 17 & 1438 & 1406 & 1446 & 1408 & 1412 & 1413 & 1450 & 1401 & 1436 \\
\hline & 18 & 1311 & 1284 & 1283 & 1283 & 1281 & 1281 & 1283 & 1287 & 1306 \\
\hline & 19 & 1081 & 1058 & 1131 & 1112 & 1131 & 1049 & 1129 & 1113 & 1075 \\
\hline & 20 & 1056 & 1039 & & 1058 & 1058 & 1027 & 1032 & 1052 & 1049 \\
\hline & 21 & 629 & 622 & 664 & 663 & 673 & 622 & 667 & 660 & 628 \\
\hline \multicolumn{11}{|c|}{ Out-of-Plane } \\
\hline$b_{1}$ & 22 & 981 & 962 & & & 985 & 987 & 842 & 986 & 998 \\
\hline & 23 & 762 & 751 & 760 & 760 & 745 & 745 & 759 & 755 & 782 \\
\hline & 24 & 370 & 362 & 369 & 372 & 369 & 376 & 370 & 370 & 375 \\
\hline$a_{2}$ & 10 & 1019 & 1002 & & & 963 & 1025 & 938 & 970 & 1039 \\
\hline & 11 & 943 & 926 & & & 765 & 945 & 861 & 786 & 949 \\
\hline & 12 & 775 & 763 & & & 785 & 729 & 753 & 775 & 793 \\
\hline & 13 & 372 & 365 & & & 377 & 367 & 410 & 363 & 372 \\
\hline
\end{tabular}

* Band affected by Fermi resonance. 
TABLE V: Computed and observed fundamental frequencies of pyrimidine. All RMS deviations exclusive of $\mathrm{C}-\mathrm{H}$ stretches and $\nu_{20}$ (see text).

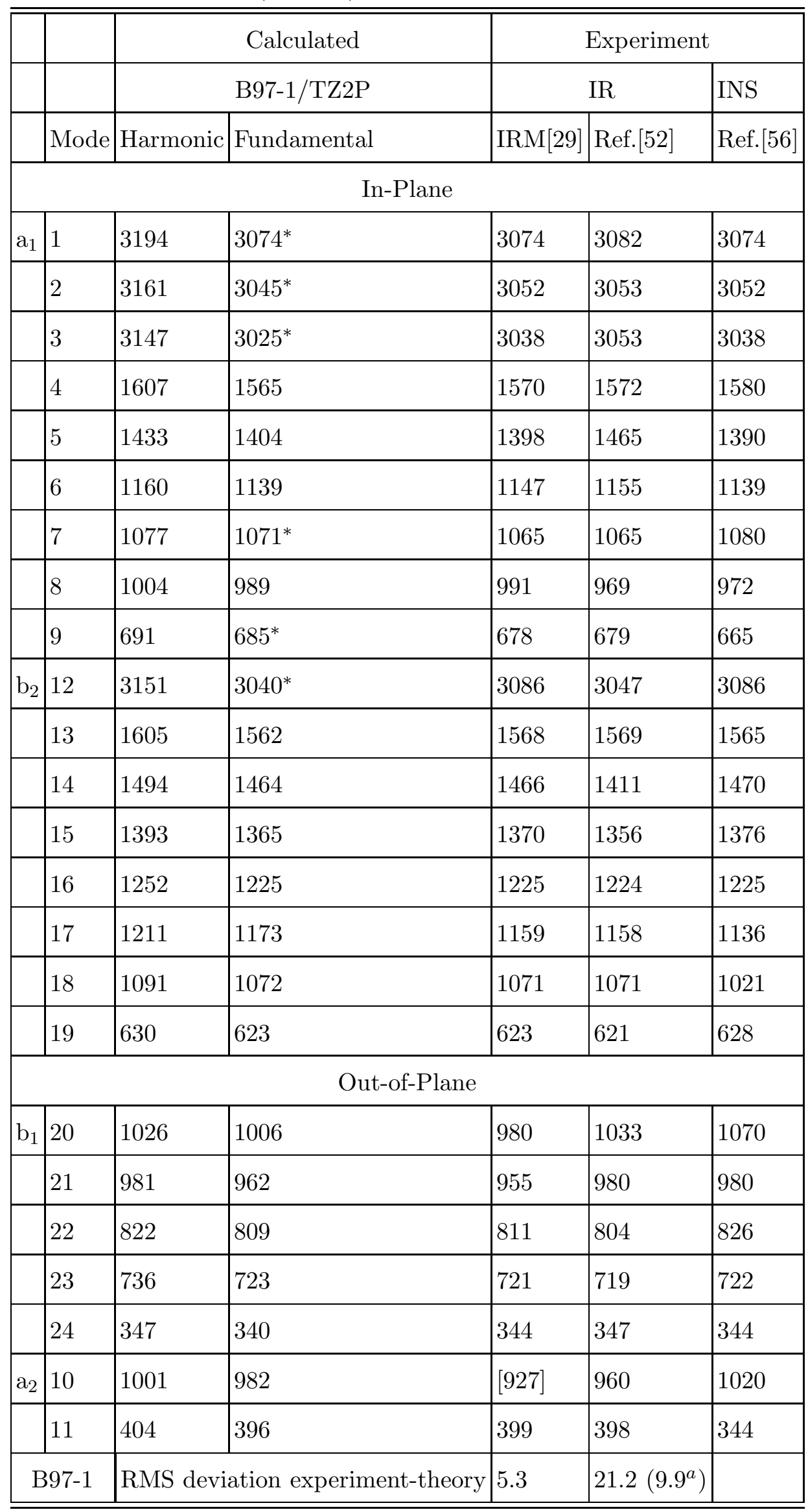

* Band affected by Fermi resonance.

${ }^{a}$ Additionally excluding $\nu_{5}$ and $\nu_{14}$. 
TABLE VI: Fermi resonances of pyrimidine.

\begin{tabular}{|l|l|l|}
\hline \multicolumn{3}{|c|}{ Resonance matrices of pyrimidine. } \\
\hline Deperturbed & $\nu_{7}$ & $\nu_{23}+\nu_{24}$ \\
\hline & 1060.0 & \\
\hline & -10.9 & 1060.1 \\
\hline
\end{tabular}

\begin{tabular}{|l|l|l|}
\hline Deperturbed & $\nu_{9}$ & $2 \nu_{24}$ \\
\hline & 682.7 & \\
\hline & 3.7 & 680.0 \\
\hline
\end{tabular}

\begin{tabular}{|l|l|l|}
\hline \multicolumn{3}{|c|}{ Eigensolutions } \\
\hline Perturbed & $\nu_{7}$ & $\nu_{23}+\nu_{24}$ \\
\hline Coefficient of & 1049.2 & 1070.9 \\
\hline$\nu_{7}$ & -0.7085 & -0.7057 \\
\hline$\nu_{23}+\nu_{24}$ & -0.7057 & -0.7085 \\
\hline
\end{tabular}

\begin{tabular}{|l|l|l|}
\hline Perturbed & $\nu_{9}$ & $2 \nu_{24}$ \\
\hline Coefficient of & 677.4 & 685.3 \\
\hline$\nu_{9}$ & -0.5760 & 0.8175 \\
\hline $2 \nu_{24}$ & 0.8175 & -0.5760 \\
\hline
\end{tabular}


TABLE VII: Computed and observed fundamental frequencies of pyrazine. All RMS deviations exclusive of $\mathrm{C}-\mathrm{H}$ stretches and $\nu_{21}$.

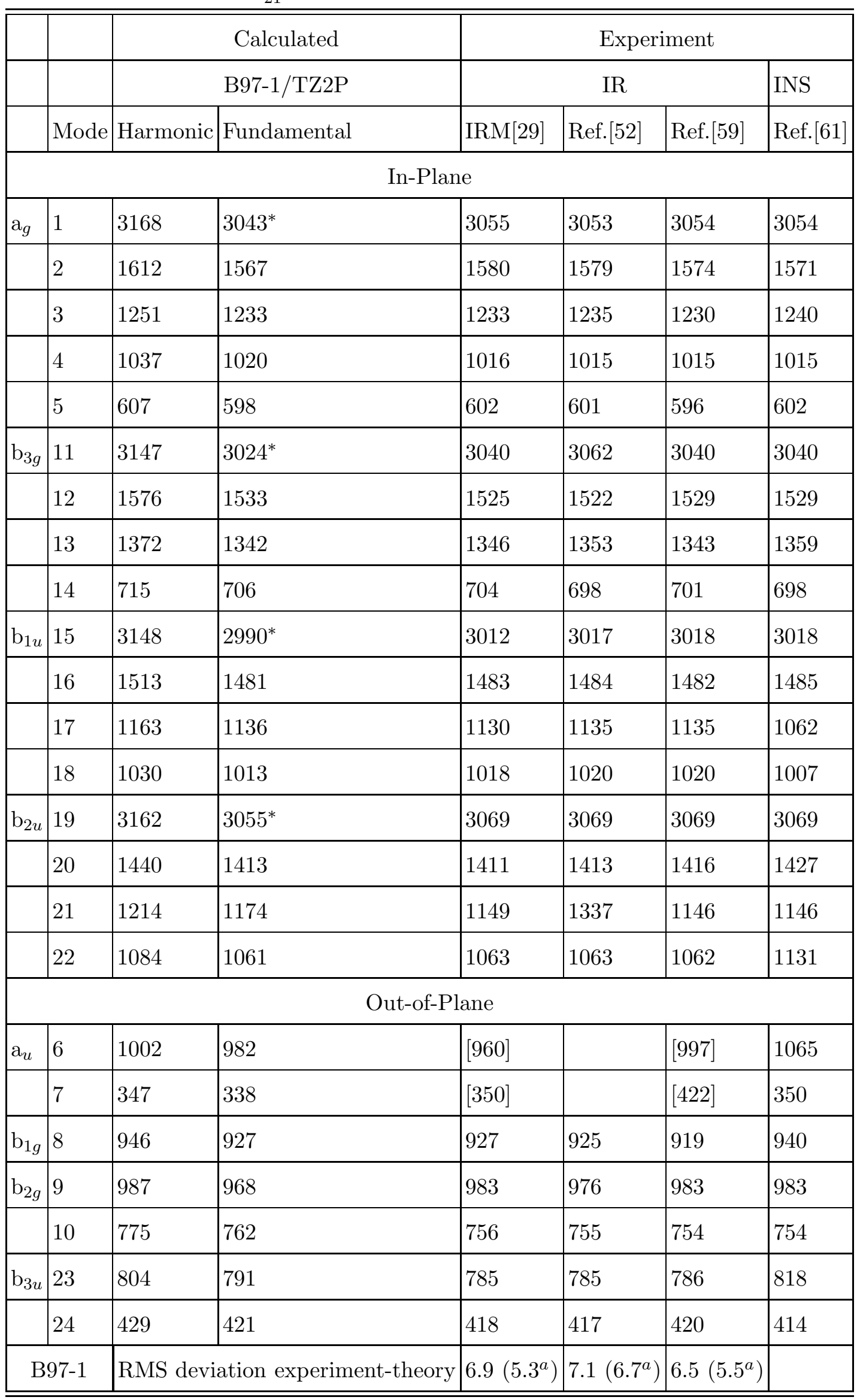

* Band affected by Fermi resonance.

${ }^{a}$ Additionally excluding $\nu_{9}$. 
TABLE VIII: Computed and observed fundamental frequencies of 1,3,5-triazine. All RMS deviations exclusive of $\mathrm{C}-\mathrm{H}$ stretches.

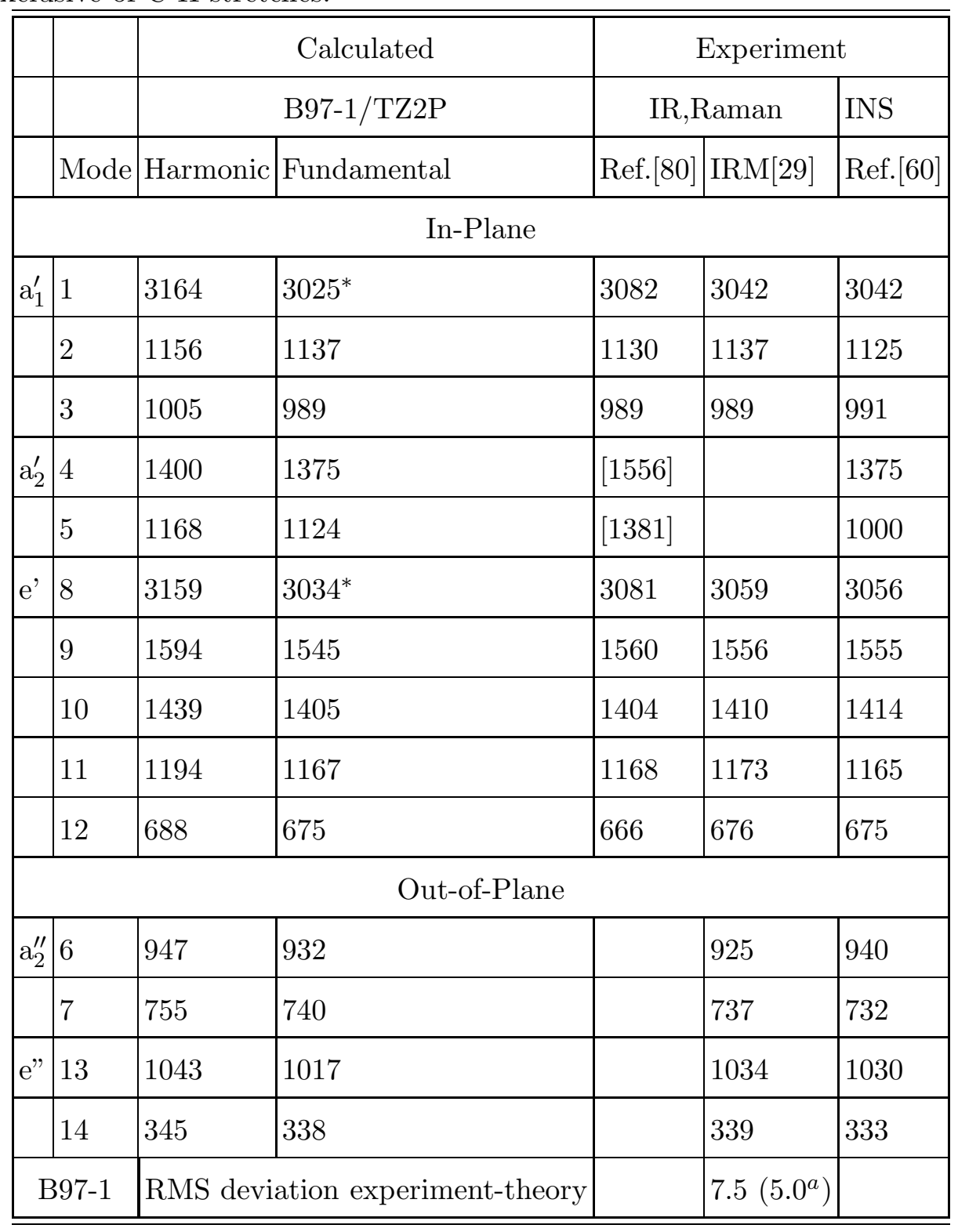

* Band affected by Fermi resonance.

${ }^{a}$ Additionally excluding $\nu_{13}$. 
TABLE IX: Computed and observed fundamental frequencies of 1,2,3-triazine. All RMS deviations exclusive of $\mathrm{C}-\mathrm{H}$ stretches.

\begin{tabular}{|c|c|c|c|c|c|c|}
\hline & & \multicolumn{2}{|r|}{ Calculated } & \multicolumn{3}{|c|}{ Experiment } \\
\hline & & \multicolumn{2}{|r|}{ B97-1/TZ2P } & IR & Raman & IR reassigned \\
\hline & Mode & Harmonic & Fundamental & Ref.[64] & Ref.[64] & \\
\hline \multicolumn{7}{|c|}{ In-Plane } \\
\hline \multirow[t]{8}{*}{$a_{1}$} & 1 & 3195 & $3032^{*}$ & 3107 & 3110 & 3046 \\
\hline & 2 & 3165 & 3028 & & 3045 & \\
\hline & 3 & 1589 & 1548 & 1597 & 1594 & 1546 \\
\hline & 4 & 1384 & 1347 & 1336 & 1329 & 1336 \\
\hline & 5 & 1136 & 1122 & 1080 & 1088 & 1124 \\
\hline & 6 & 1092 & $1081^{*}$ & 1069 & 1064 & 1080 \\
\hline & 7 & 1006 & 985 & 979 & 977 & 979 \\
\hline & 8 & 675 & 667 & 660 & 660 & 660 \\
\hline \multirow[t]{7}{*}{$b_{2}$} & 14 & 3171 & $3042^{*}$ & 3046 & & 3046 \\
\hline & 15 & 1584 & 1538 & 1545 & 1547 & 1545 \\
\hline & 16 & 1438 & 1410 & 1410 & & 1410 \\
\hline & 17 & 1219 & 1199 & 1195 & 1198 & 1195 \\
\hline & 18 & 1101 & 1078 & 1124 & 1127 & 1080 \\
\hline & 19 & 974 & 929 & 935 & & 935 \\
\hline & 20 & 662 & $659^{*}$ & 653 & & 660 \\
\hline \multicolumn{7}{|c|}{ Out-of-Plane } \\
\hline$b_{1}$ & 10 & 1017 & 998 & & & \\
\hline & 11 & 824 & 811 & 819 & & 819 \\
\hline & 12 & 783 & 769 & 769 & & 769 \\
\hline & 13 & 302 & 296 & {$[318]$} & & \\
\hline$a_{2}$ & 8 & 992 & 973 & & & \\
\hline & 9 & 358 & 350 & & 365 & \\
\hline & 397-1 & RMS devi & iation experiment-theory & 22.1 & & 5.2 \\
\hline
\end{tabular}

* Band affected by Fermi resonance. 
TABLE X: Fermi resonances of 1,2,3-triazine.

\begin{tabular}{|l|l|l|}
\hline \multicolumn{3}{|c|}{ Resonance matrices of $1,2,3$-triazine. } \\
\hline Deperturbed & $\nu_{6}$ & $\nu_{12}+\nu_{13}$ \\
\hline & 1074.5 & \\
\hline & 10.6 & 1061.4 \\
\hline
\end{tabular}

\begin{tabular}{|l|l|l|}
\hline Deperturbed & $\nu_{20}$ & $\nu_{9}+\nu_{13}$ \\
\hline & 655.1 & \\
\hline & -6.3 & 647.6 \\
\hline
\end{tabular}

\begin{tabular}{|l|l|l|}
\hline \multicolumn{3}{|c|}{ Eigensolutions. } \\
\hline Perturbed & $\nu_{6}$ & $\nu_{12}+\nu_{13}$ \\
\hline Coefficient of & 1055.5 & 1080.7 \\
\hline$\nu_{6}$ & -0.4804 & -0.8770 \\
\hline$\nu_{12}+\nu_{13}$ & 0.8770 & -0.4804 \\
\hline
\end{tabular}

\begin{tabular}{|l|l|l|}
\hline Perturbes & $\nu_{20}$ & $\nu_{9}+\nu_{13}$ \\
\hline Coefficient of & 644.0 & 658.7 \\
\hline$\nu_{9}$ & 0.4939 & -0.8695 \\
\hline$\nu_{9}+\nu_{13}$ & 0.8175 & 0.4939 \\
\hline
\end{tabular}


TABLE XI: Computed and observed fundamental frequencies of 1,2,4-triazine. All RMS deviations exclusive of $\mathrm{C}-\mathrm{H}$ stretches.

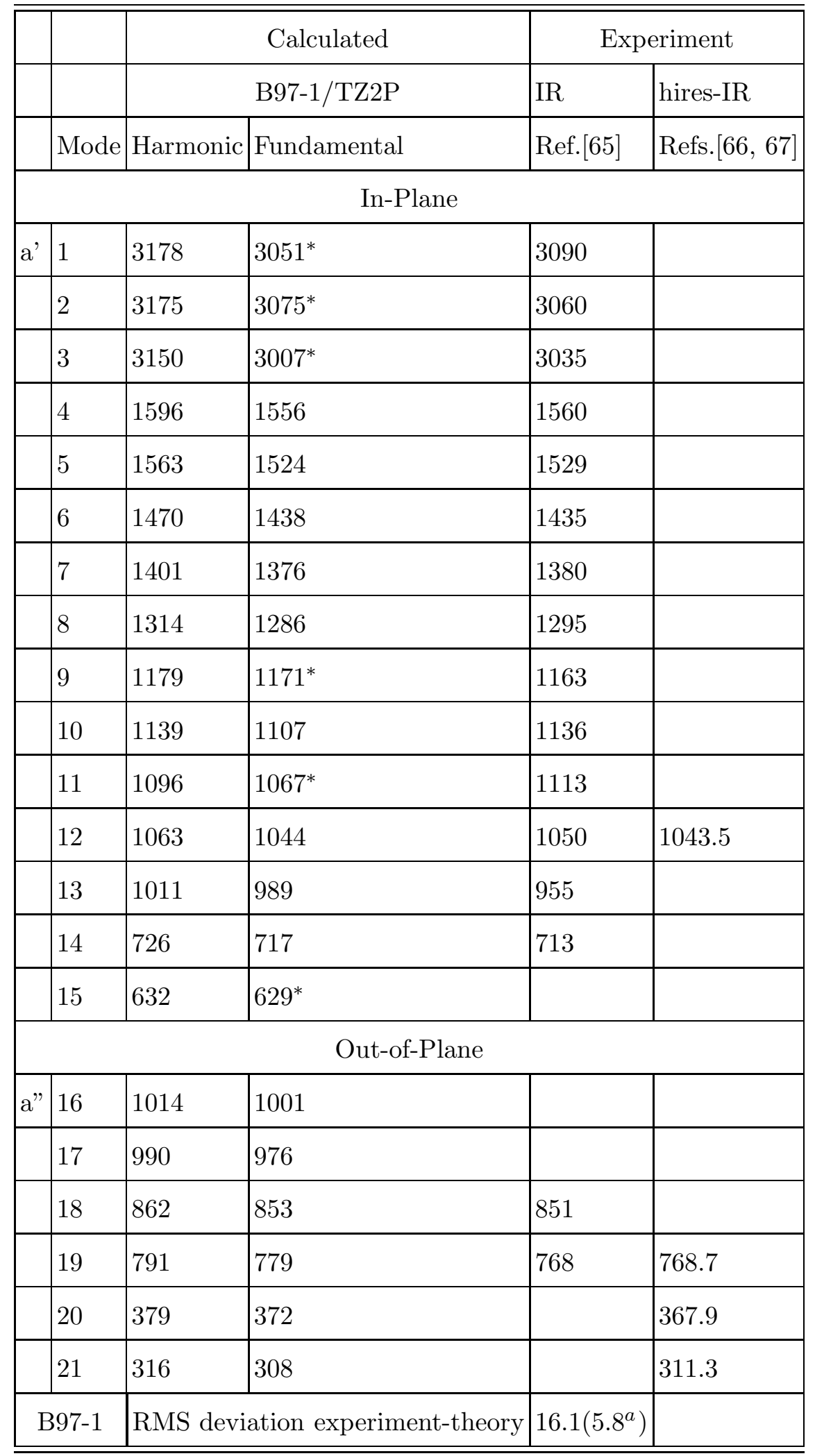

* Band affected by Fermi resonance.

a Additionally excluding $\nu_{11} ; 1113 \mathrm{~cm}^{-1}$ band reassigned to $\nu_{10}$. 
TABLE XII: Fermi resonances of 1,2,4-triazine.

\begin{tabular}{|l|l|l|}
\hline \multicolumn{3}{|c|}{ Resonance matrices of $1,2,4$-triazine. } \\
\hline Deperturbed & $\nu_{11}$ & $\nu_{17}+\nu_{21}$ \\
\hline & 1160.4 & \\
\hline & -13.7 & 1153.4 \\
\hline
\end{tabular}

\begin{tabular}{|l|l|l|}
\hline Deperturbed & $\nu_{15}$ & $2 \nu_{21}$ \\
\hline & 622.8 & \\
\hline & 8.4 & 617.7 \\
\hline
\end{tabular}

\begin{tabular}{|l|l|l|}
\hline \multicolumn{3}{|c|}{ Eigensolutions } \\
\hline Perturbed & $\nu_{11}$ & $\nu_{17}+\nu_{21}$ \\
\hline Coefficient of & 1142.7 & 1171.0 \\
\hline$\nu_{11}$ & 0.6136 & -0.7896 \\
\hline$\nu_{17}+\nu_{21}$ & 0.7896 & 0.6136 \\
\hline
\end{tabular}

\begin{tabular}{|l|l|l|}
\hline Perturbed & $\nu_{15}$ & $2 \nu_{21}$ \\
\hline Coefficient of & 611.4 & 629.0 \\
\hline$\nu_{9}$ & -0.5949 & 0.8038 \\
\hline $2 \nu_{21}$ & 0.8038 & -0.5949 \\
\hline
\end{tabular}


TABLE XIII: Harmonic frequencies of 1,2,4,5-tetrazine.

\begin{tabular}{|c|c|c|c|c|c|c|c|}
\hline & CCSD & \multicolumn{4}{|c|}{$\operatorname{CCSD}(\mathrm{T})$} & B3LYP & B97-1 \\
\hline & \multicolumn{3}{|c|}{$6-311 \mathrm{G}^{* *}$} & cc-pVTZ & ANO-4321 & \multirow{2}{*}{\begin{tabular}{|l} 
cc-pVTZ \\
$30]$
\end{tabular}} & \multirow[t]{2}{*}{ TZ2P } \\
\hline & {$[25]$} & Full[25] & & \multicolumn{2}{|c|}{ Frozen-core } & & \\
\hline \multicolumn{8}{|c|}{ In-Plane } \\
\hline \multirow[t]{4}{*}{$\mathrm{a}_{g}$} & 3253 & 3223 & 3221 & 3223 & 3226 & 3196 & 3192 \\
\hline & 1524 & 1456 & 1452 & 1455 & 1457 & 1472 & 1473 \\
\hline & 1059 & 1018 & 1018 & 1025 & 1025 & 1050 & 1047 \\
\hline & 758 & 741 & 740 & 747 & 745 & 756 & 751 \\
\hline \multirow[t]{3}{*}{$\mathrm{b}_{1 u}$} & 3251 & 3222 & 3218 & 3222 & 3225 & 3199 & 3191 \\
\hline & 1250 & 1212 & 1210 & 1218 & 1216 & 1232 & 1231 \\
\hline & 1109 & 1088 & 1088 & 1096 & 1098 & 1099 & 1096 \\
\hline \multirow[t]{3}{*}{$\mathrm{b}_{2 u}$} & 1505 & 1471 & 1465 & 1472 & 1470 & 1479 & 1478 \\
\hline & 1167 & 1137 & 1134 & 1138 & 1137 & 1151 & 1147 \\
\hline & 845 & 908 & 905 & 932 & 927 & 964 & 969 \\
\hline \multirow[t]{3}{*}{$\mathrm{b}_{3 g}$} & 1611 & 1558 & 1552 & 1561 & 1561 & 1559 & 1560 \\
\hline & 1345 & 1321 & 1319 & 1323 & 1323 & 1330 & 1325 \\
\hline & 648 & 637 & 635 & 640 & 640 & 656 & 650 \\
\hline \multicolumn{8}{|c|}{ Out-of-Plane } \\
\hline$a_{u}$ & 344 & 257 & 319 & 344 & 346 & 354 & 344 \\
\hline \multirow[t]{2}{*}{$\mathrm{b}_{2 g}$} & 985 & 947 & 957 & 998 & 996 & 1011 & 999 \\
\hline & 803 & 772 & 783 & 816 & 816 & 837 & 829 \\
\hline \multirow[t]{2}{*}{$\mathrm{b}_{3 u}$} & 930 & 896 & 904 & 919 & 921 & 940 & 930 \\
\hline & 297 & 228 & 270 & 276 & 270 & 258 & 250 \\
\hline
\end{tabular}


TABLE XIV: Computed and observed fundamental frequencies of 1,2,4,5-Tetrazine. For RMS deviations, values in parentheses are exclusive of $\mathrm{C}-\mathrm{H}$ stretching frequencies.

\begin{tabular}{|c|c|c|c|c|c|c|c|}
\hline & & \multicolumn{2}{|r|}{ Calculated } & \multicolumn{4}{|c|}{ Experiment } \\
\hline & Mode & B97-1 & $\operatorname{CCSD}(\mathrm{T}) / \mathrm{B} 97-1$ & $\operatorname{IRM}[29]$ & Ref.[81] & $\mathrm{SP}[74]$ & FMI $[76]$ \\
\hline \multicolumn{8}{|c|}{ In-Plane } \\
\hline \multirow[t]{4}{*}{$\mathrm{a}_{g}$} & 1 & 3073 & 3107 & 3010 & 3040 & 3089 & 3090 \\
\hline & 2 & 1424 & 1408 & 1415 & 1489 & $1417^{c}$ & $1418^{c}$ \\
\hline & 3 & 1024 & 1000 & 1009 & 990 & 1015 & 1017 \\
\hline & 4 & 741 & 735 & 736 & 737 & 734 & 736 \\
\hline \multirow[t]{3}{*}{$\mathrm{b}_{1 u}$} & 11 & 3070 & 3104 & 3086 & 3070 & 3086 & 3090 \\
\hline & 12 & 1204 & 1189 & 1204 & 1200 & 1204 & 1200 \\
\hline & 13 & 1079 & 1081 & 1093 & 1106 & $1109^{d}$ & $1103^{d}$ \\
\hline \multirow[t]{3}{*}{$\mathrm{b}_{2 u}$} & 14 & 1445 & 1437 & 1448 & 1434 & 1448 & 1440 \\
\hline & 15 & $1112^{*}$ & 1102 & 1108 & 1187 & 1151 & \\
\hline & 16 & 927 & 885 & 883 & 1085 & $893^{d}$ & $881^{d}$ \\
\hline \multirow[t]{3}{*}{$\mathrm{b}_{3 g}$} & 8 & 1511 & 1511 & 1525 & 1543 & $1523^{c}$ & $1521^{c}$ \\
\hline & 9 & 1294 & 1293 & 1290 & 1278 & 1302 & 1303 \\
\hline & 10 & 645 & 638 & 640 & 679 & 649 & 651 \\
\hline \multicolumn{8}{|c|}{ Out-of-Plane } \\
\hline$a_{u}$ & 5 & 336 & 338 & 335 & 319 & 335 & 335 \\
\hline \multirow[t]{2}{*}{$\mathrm{b}_{2 g}$} & 6 & 977 & 974 & 994 & 925 & 1015 & \\
\hline & 7 & 814 & 801 & 801 & 775 & 799 & 800 \\
\hline \multirow[t]{2}{*}{$\mathrm{b}_{3 u}$} & 17 & 911 & 902 & 929 & 890 & 929 & 904 \\
\hline & 18 & 244 & 261 & 254 & 340 & 254 & 254 \\
\hline \multirow{2}{*}{\multicolumn{4}{|c|}{$\begin{array}{c}\text { RMS dev. from } \nu_{i}(\mathrm{~B} 97-1 / \mathrm{TZ} 2 \mathrm{P}) \\
\omega_{i}(\mathrm{CCSD}(\mathrm{T}) / \mathrm{ANO} 4321)+\nu_{i}-\omega_{i}(\mathrm{~B} 97-1 / \mathrm{TZ} 2 \mathrm{P})\end{array}$}} & $15.2^{a}\left(15.1,14.8^{b}\right)$ & $54.8(57.5)$ & $19.0(19.4)$ & $16.0(15.6)$ \\
\hline & & & & $12.2^{a}\left(11.3,9.4^{b}\right)$ & $63.5(64.5)$ & $20.1(20.3)$ & $11.0(10.2)$ \\
\hline
\end{tabular}

* Band affected by Fermi resonance.

${ }^{a}$ Reassigning Mode 1 to $3090 \mathrm{~cm}^{-1}$.

${ }^{b}$ Excluding also Mode 17.

${ }^{c}$ These assignments swapped based on IRM and our calculations.

${ }^{d}$ These assignments swapped based on IRM and our calculations. 